\title{
SIGNA EQUITUM EN EL MUNDO IBÉRICO. LOS BRONCES TIPO "JINETE DE LA BASTIDA" Y EL INICIO DE LA ARISTOCRACIA ECUESTRE IBÉRICA
}

\author{
ALBERTO J. LORRIO ALVARADO* \\ Universidad de Alicante \\ MARTÍN ALMAGRO-GORBEA \\ Real Academia de la Historia
}

\begin{abstract}
Estudio de un tipo de pequeños bronces ibéricos que representan un jinete desnudo con casco jonio-ibérico con alta cimera y otras armas, dispuesto sobre un soporte de volutas protoeólicas con un vástago para su enmangue en un astil de madera. Se ha denominado tipo "Jinete de La Bastida" por ser éste el mejor de los ejemplares. El conjunto es homogéneo por su iconografía y estilo jonio-ibérico, que se fecha a partir del 475-450 a.C., pues alguna pieza puede ser algo posterior a esta fecha. Su similitud estructural con los signa equitum celtibéricos del siglo II a.C. permite interpretar estos bronces como signa equitum o estandartes ibéricos, pertenecientes a elites aristocráticas ecuestres, cuyo heros equitans o antepasado mítico representarian estas figuras.
\end{abstract}

Su distribución desde las zonas mediterráneas hasta Andalucía central documenta la penetración de elites filo-helenas ibéricas que explicarian las influencias culturales y lingüisticas ibéricas en las áreas occidentales de Tartessos.

Analysis of a "La Bastida"-type bronze figures representing a nude rider with a GraecoIberian helmet and other weapons on a stand with a double proto-aeolic capital. The set is homogeneous and can be dated after $475-450 \mathrm{BC}$ by its Graeco-Iberian style.

These bronzes are similar to some 2 nd century BC Celtiberian signa equitum, which means they can be interpreted as Iberian standards or signa equitum decorated with the figure of the Hero equitans, the mythical ancestor of the aristocratic rulers of Iberian society.

Their pattern of distribution from the Mediterranean regions to central Andalusia is evidence of the penetration of Iberian elites and would explain Iberian cultural and linguistic influences in the western Tartessian area.

El "Jinete de La Bastida", asi denominado por haber sido hallado en 1931 en el yacimiento valenciano de La Bastida de les Alcuses, Mogente (Ballester, 1932, 27, lám. V,1), es uno de los bronces ibéricos más populares y conocidos. Kukahn (1954), al estudiar esta interesante pieza, señaló su proximidad a los bronces jonio-ibéricos que constituyen las mejores creaciones de la pequeña broncística ibérica, pero nunca se ha entrado a fondo a analizar su función y significado, considerándose genéricamente como un "exvoto", aunque su procedencia de un poblado no fuera la habitual para este tipo de piezas.

En fechas recientes, el estudio que hemos llevado de algunos materiales conservados en los fondos del Museo Arqueológico de Cuenca ha permitido identificar una serie de figurillas de bronce de morfología muy semejante conservadas en museos y en colecciones particulares, que constituyen los paralelos de esa destacada figura ${ }^{1}$. En todos los casos,
* Este trabajo se ha realizado en el marco del proyecto de investigación BHA2003-08222 Meseta-Mediterráneo. De la Edad del Bronce a la aparición de la escritura. Tradiciones culturales, intercambios y procesos de transformación, financiado por la DGICYT del Ministerio de Ciencia y Tecnología y fondos FEDER.

1 Agradecemos a la Dra. Helena Bonet, directora del Museo de Prehistoria de Valencia, quien nos facilitó el estudio del "Jinete de la Bastida", proporcionándonos las fotografías de la pieza que reproducimos en este trabajo, permitiéndonos, asimismo, acceder a la documentación inédita sobre dicho yacimiento. Igualmente, a D. ${ }^{a}$ Concepción Rodríguez, directora del Museo de Cuenca, y a D. Juan Manuel Millán, Técnico de dicha Institución, las facilidades dadas para realizar el estudio de la pieza depositada en el citado Museo, así como a D. Raúl Cruz, arqueólogo de la Unidad de Patrimonio de la Delegación Provincial de Cuenca, por la información relativa al decomiso del conjunto de materiales entre los que se encontraba dicha pieza. Asimismo, queremos manifestar nuestro agradecimiento al Dr. Mariano Fernández Fairén, por su generosidad y por su ayuda para conseguir los datos relativos a los ejemplares de la zona de Espejo. También al Dr. Ignacio Montero quien realizó los análisis metalográficos de dichas piezas. Finalmente, a $D^{a}$. M. ${ }^{2} D$. Sánchez de Prado, a quien se deben los dibujos a línea de las piezas estudiadas. 
se reproducen jinetes desnudos armados y tocados con un casco de alta cimera, como el Jinete de La Bastida. El análisis de conjunto ayuda a precisar el origen, función y significado de estas piezas como probables signa equitum ibéricos, lo que ha aconsejado darlas a conocer por representar una interesante aportación al conocimiento del mundo ibérico y de sus elites ecuestres, tan valoradas en estos últimos años.

\section{DESCRIPCIÓN}

\section{1. "Jinete de La Bastida"}

La figurilla de jinete procedente del poblado ibérico de La Bastida de Les Alcuses, Mogente, Valencia (Ballester, 1932, lám. V,I,2; Kukahn, 1954; Tarradell, 1968, fig. 18; Nicolini, 1969, lám. 1, 6-7; id., 1973, lám. 1; id., 1977, $82, n^{\circ} 22$; etc.), es la más conocida, aunque también la que más diferencias presenta en este conjunto de piezas ecuestres de bronce ibéricas (Fig. 1). Apareció el 21 de julio de 1931 en el departamento 218 (Ballester, 1931, 47 s.; Dies Cusí y Álvarez García, 1998, 334) pasando desde entonces a formar parte de los fondos del Museo de Prehistoria de Valencia (Inv. $\left.\mathrm{n}^{\circ} 2.899\right)$.

Se trata de un caballero desnudo tocado con un casco de alta cimera, lo que le asemeja a las restantes piezas estudiadas, aunque a diferencia de ellas aparece armado con una falcata y un escudo redondo, presentando, igualmente, una diferente pose, condicionada por la presencia de dichas armas. Está erguido sobre el caballo, con el cuerpo muy ligeramente inclinado hacia delante, observándose una mayor tensión en el lado derecho -como demuestra la posición del brazo, relacionada con la forma de empuñar la espada, y de la piernaque en el izquierdo, más relajado, pues se limita a sostener el escudo y las riendas. Efectivamente, el brazo derecho, echado hacia atrás, se dobla por el codo en un ángulo agudo muy forzado, que le permite portar la falcata en posición horizontal, apoyándola sobre el muslo; la mano está representada sobre la empuñadura, con el pulgar claramente individualizado, rasgo éste característico de alguna de las piezas estudiadas (vid. infra $\mathrm{n}^{\circ} 2$ ). El brazo izquierdo, separado igualmente del cuerpo, se extiende hacia adelante de forma oblicua, sosteniendo un escudo redondo y seguramente también las riendas, muy cerca del bocado (Kukahn,
1954, 149). Las piernas aparecen dobladas, en ángulo recto la derecha, sobre la que apoya la falcata, y más abierto la izquierda, colgando ambas en contacto con las patas delanteras del caballo; los pies están diferenciados. La falcata está representada de forma esquemática, aunque sea perfectamente observable la característica curvatura de la hoja, así como la empuñadura. Sobre el muslo izquierdo se ha representado un objeto en disposición transversal, ligeramente oblicuo, que cabría interpretar como la vaina del arma, aunque resulte algo más corta que aquélla; presenta forma y sección rectangular, con su extremo distal, interpretable como la contera, redondeado. Por su parte, el escudo, de forma circular, se ha representado con el umbo, también circular.

El rostro del jinete presenta nariz recta, ojos almendrados muy marcados y boca con una ligera sonrisa hierática, teniendo el mentón diferenciado. La cabeza se apoya sobre un fuerte cuello troncocónico. Está tocado con un casco, de forma redondeada, con reborde resaltado, evidente en la zona del guardanuca y los laterales, pero ausente en el contorno de la cara. Esta rematado por un penacho o alta cimera, que ofrece una amplia base sobre la que se eleva, prolongándose hacia delante y cayendo por detrás de la cabeza, en contacto con el casquete, hasta la altura de los hombros, donde se dobla ligeramente hacia fuera, apoyándose en el codo derecho del caballero.

El caballo presenta una clara desproporción con el jinete, lo que también caracteriza a los otros ejemplares estudiados, resultando notablemente pequeño. Tiene los cuartos traseros algo bajos, con lo que los glúteos del jinete quedan resaltados. Las patas son cilíndricas. La cola se levanta ligeramente, quedando algo separada del cuerpo, para, posteriormente, caer verticalmente entre ambas patas, uniéndose a ellas en su tramo final. La cabeza, levemente ladeada hacia la derecha, ofrece mayor detalle, habiéndose representado las orejas, puntiagudas, asi como los ojos, la nariz y la boca, entreabierta. El caballo presenta sobre la frente lo que cabe interpretar como un peinado que divide el flequillo por la mitad enroscándose las puntas en sendos rizos, dirigidos hacia delante, lo que se aprecia mejor en el lado derecho, dada la presencia del escudo en el izquierdo. Este es un detalle muy característico de ciertas esculturas ibéricas (vid. infra, $\S 2$ ). Las riendas, rectas, son observables a ambos lados del cuello del animal -en el derecho se han reproducido incluso por detrás de 

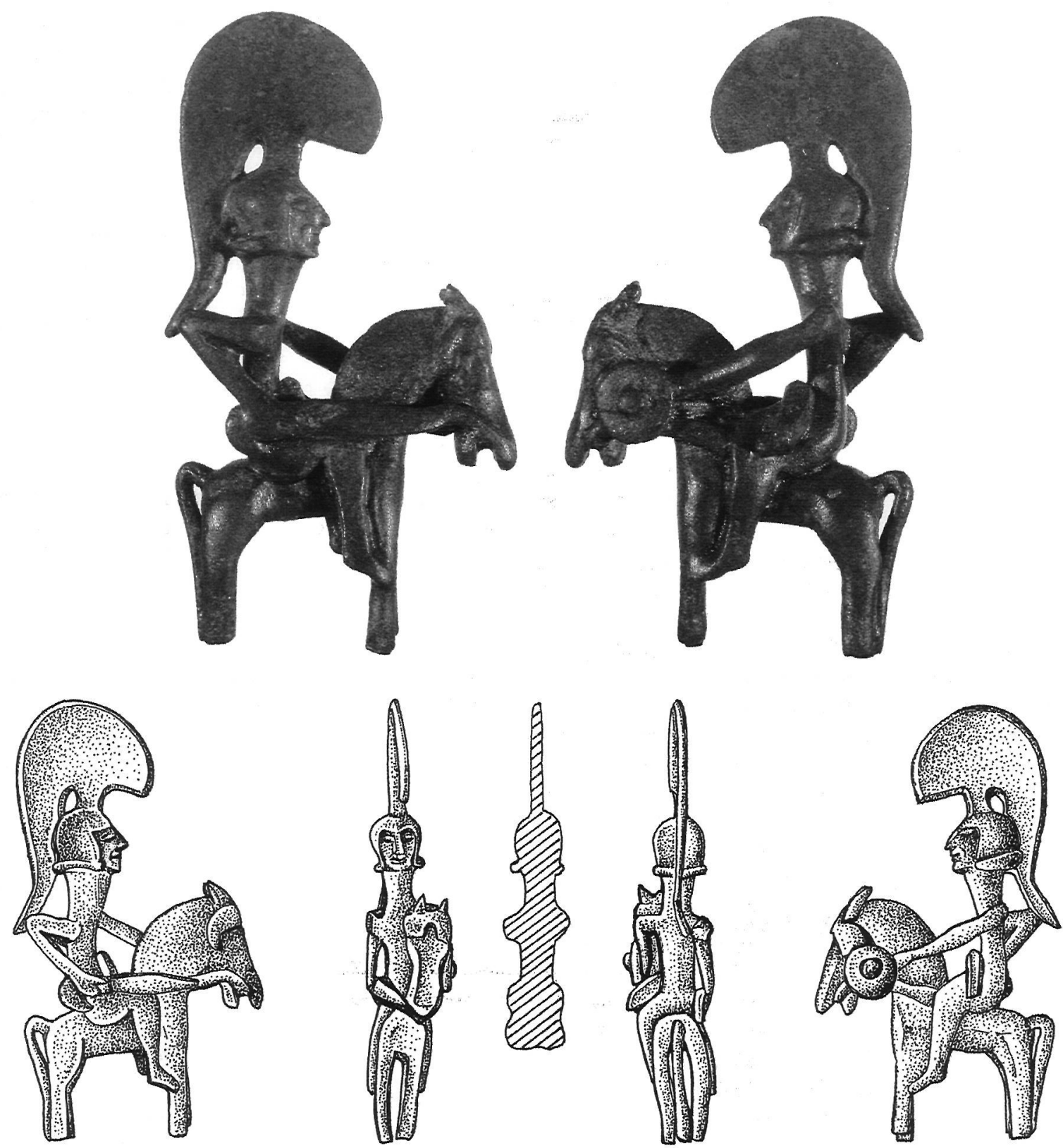

Figura 1: “Jinete de la Bastida”. (Foto S.I.P.).

la falcata-, elevándose ligeramente en dirección al freno, observándose una marcada inflexión hacia la boca del caballo. El caballo aparece ligeramente desplazado hacia la izquierda del jinete.

La figura carece de la base con las volutas y del tubo de enmangue característicos de las restantes piezas estudiadas (vid. infra), lo que en principio podría hacer pensar en una funcionalidad diferente para este ejemplar. Pero su inspección visual permite suponer una posible rotura de la base, observable en la pata delantera izquierda del caballo, más corta que la derecha, que, a su vez, presenta una superficie oblicua, o en las patas traseras, ligeramente desiguales, aspectos que, junto a la tendencia convergente de las patas, estrechándose ligeramente hacia la zona de las pezuñas, son difícilmente explicables si la pieza hubiera sido concebida como una figura exenta, pues impiden crear una base estable, imposibilitando, como así ocurre, que la pieza pueda sostenerse sin la ayuda de un soporte. La conservación de la pieza es buena. 
Dimensiones: altura conservada, $7,3 \mathrm{~cm}$; anchura máxima, $1,5 \mathrm{~cm}$; longitud máxima, $4 \mathrm{~cm}$; peso, $53,58 \mathrm{gr}$.

\section{2. "Jinete del Museo de Cuenca"}

Esta pieza se conserva en el Museo de Cuenca desde el año 2001 (Inv. $n^{\circ}$ 1.598). Procede del mercado ilegal de antigüedades, habiendo ingresado en la citada institución gracias al decomiso de una importante colección privada de la Puebla del Salvador (Cuenca) ${ }^{2}$, integrada por más de un millar de piezas expoliadas en yacimientos de La Manchuela conquense. Aunque el lugar del hallazgo no sea conocido, las referencias iniciales lo situaban hacia la zona de Iniesta ${ }^{3}$, en el Sureste de Cuenca, pudiendo proceder, según noticia sin confirmar, de una necrópolis localizada al sureste de la localidad de Castillejo de Iniesta (vid. infra $\S 3)$. La riqueza arqueológica de esta zona de La Manchuela es conocida gracias a los trabajos de excavación realizados en algunas necrópolis del término municipal de Iniesta, objeto igualmente de expolios (Valero, 1999, 182), que también han afectado a otros cementerios de esta comarca, como sería el caso de algunos localizados en los términos municipales de Olmedilla de Alarcón (vid. infra § 3 ) o Campillo de Altobuey, así como de zonas colindantes, lo que hemos podido constatar en nuestros trabajos de prospección en el término municipal de Mira, Cuenca, o en nuestras excavaciones en el poblado y la necrópolis de El Molón, Camporrobles, Valencia (Lorrio, 2001, 166), en el noroeste de la comarca valenciana de UtielRequena.

Es una figurilla realizada en bronce fundido, que ha sido retocada mediante cincelado, pues se observan una serie de marcas oblicuas sobre la rodilla izquierda, que pudieran ser posteriores a su fabricación. Representa un guerrero desnudo montado sobre un caballo de pequeño tamaño, desproporcionado en relación al jinete (Fig. 2). El caballero está en posición erguida, con la cabeza ligeramente inclinada hacia adelante, los brazos doblados en ángulo y las manos extendidas, con los pulgares separados -aunque en la mano izquierda este detalle queda indicado con un ligero ensanchamiento-, sosteniendo las riendas, que se sitúan en posición prácticamente horizontal. Las piernas se doblan en ángulo -recto, la izquierda, y algo más abierto, la derecha-, colgando junto a las patas delanteras del caballo, con las que están en contacto. La pierna izquierda presenta un tratamiento más cuidado, marcando muslos y pantorrilla. Los pies están diferenciados. El rostro está representado con un cierto detalle, presentando una nariz recta, ojos almendrados grandes y sobresalientes, boca pequeña, de contornos marcados, y mentón diferenciado. Porta un casco, de forma redondeada, con guardanuca y borde resaltado, coronado por una alta cimera o penacho de amplia base, que cae elegantemente por detrás de la cabeza, sin tocar el capacete, doblándose hacia el exterior a la altura de los hombros.

El caballo está representado en actitud de descanso, apoyado sobre las patas firmemente, con la cabeza levantada, la curva de los cuartos traseros individualizada y la larga cola pegada al cuerpo, cayendo entre las patas traseras del animal. El cuerpo es corto y tiene forma cilíndrica, al igual que las patas. Presenta la curva de la cerviz muy marcada, lo que le asemeja a las restantes piezas (vid. infra $\left.n^{\circ} 1,3-4\right)$. Está embridado y porta un elegante tocado a modo de creciente que oculta las orejas, observándose a cada lado de la cabeza una línea facetada situada a la altura de los ojos, no indicándose nariz y boca. Se alza sobre dos pares de volutas, con las patas traseras y delanteras descansando entre los respectivos pares de hojas, que cabe interpretar como la esquematización de sendos capiteles protoeólicos (vid. infra, § 2), que surgen desde las esquinas de una plataforma horizontal de forma rectangular, con una arista que la recorre longitudinalmente por su zona central, sostenida, a su vez, por un vástago de forma cilíndrica, hueco en su parte inferior, lo que sugiere la forma de un árbol del que surgirian las referidas hojas. Dicho vástago está ligeramente ensanchado en su extremo superior, adoptando

\footnotetext{
${ }^{2}$ La pieza forma parte de un lote intervenido por el Grupo de Patrimonio Histórico de la Unidad Central Operativa de la Guardia Civil, diligencia policial $n^{\circ} 12 / 01$, el 27 de marzo de 2001.

${ }^{3}$ Asi aparece recogido en el extenso articulo publicado el 14 de febrero de 2001 (pág. 23) en "El Día" de Cuenca, en el que se daba cuenta de la operación policial que llevó a la recuperación de la pieza. Tal procedencia explicaria la publicación de una fotografía de la figurita de jinete, junto a las de otros objetos que formaban parte del mismo decomiso, en un tríptico del Museo Arqueológico de Iniesta, en cuyo texto, sin embargo, no se hace referencia alguna sobre las mismas.
} 

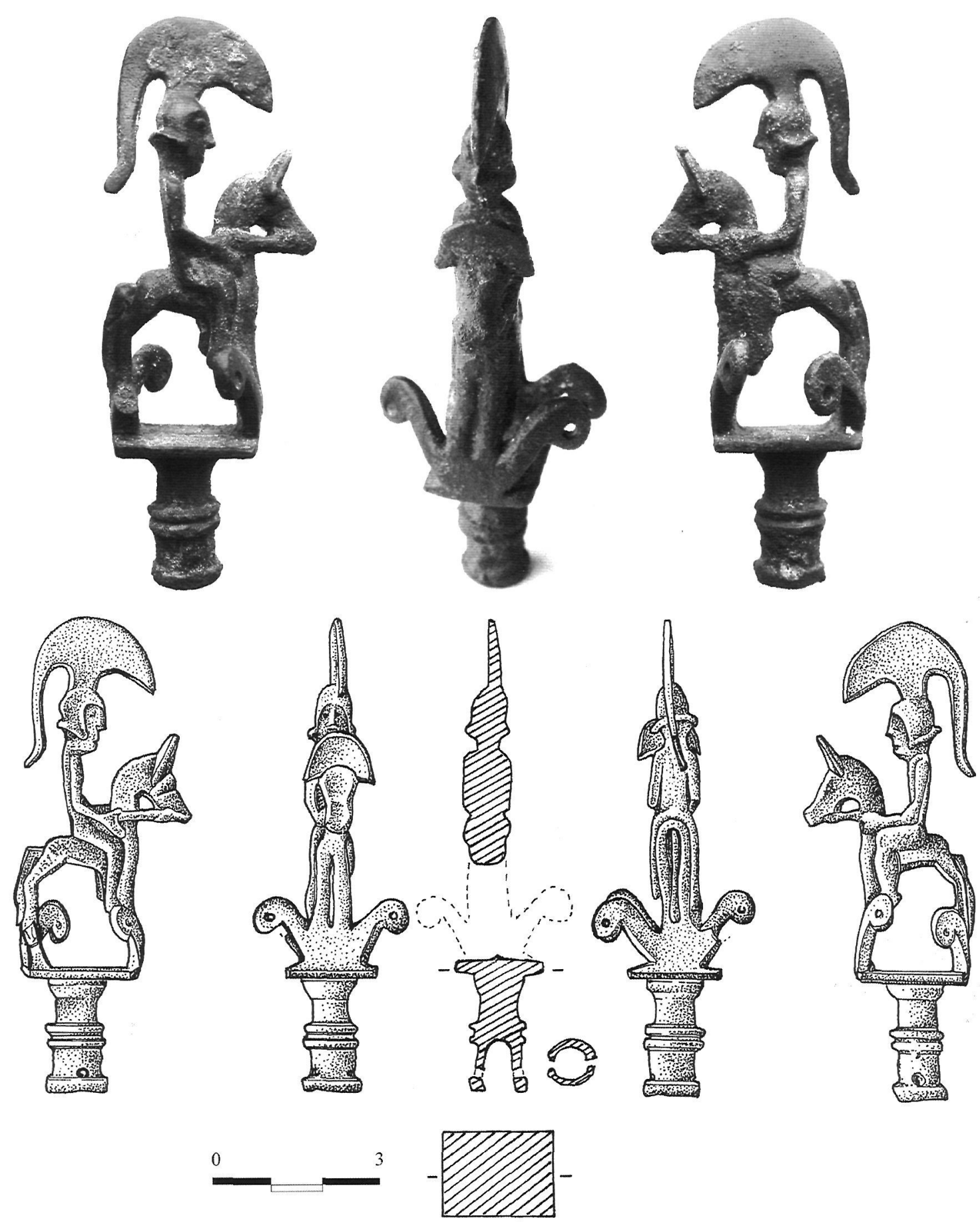

Figura 2: "Jinete del Museo de Cuenca", antes de ser restaurado. (Junta de Comunidades de Castilla-La Mancha).

forma troncocónica. Presenta dos molduras anulares en la parte central, así como, otra, en la parte inferior, todas ellas de diámetros similares; junto a la base, se documentan dos perforaciones diametralmente opuestas, que permitirían la fijación de la pieza a un astil de madera, mediante una o dos piezas metálicas, que no se han conservado. Aunque falta una de las volutas traseras, la conservación de la pieza es buena.

Dimensiones: altura total, $8,5 \mathrm{~cm}$; altura hasta la base del soporte, $6,5 \mathrm{~cm}$; altura del cilindro, $2 \mathrm{~cm}$; anchura máxima (volutas), $3 \mathrm{~cm}$; longitud máxima (caballo), $3,15 \mathrm{~cm}$; dimensiones de la base, 1,75 x 2,13 cm; diámetro del cilindro, $1,1 \mathrm{~cm}$; grosor (cilindro), $0,2 \mathrm{~cm}$; peso, $52,6 \mathrm{gr}$. 


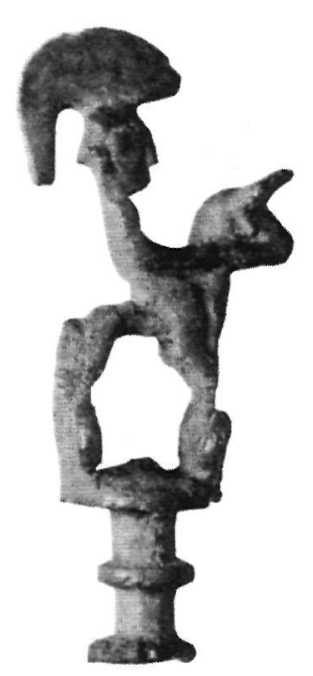

Figura 3: "Jinete Saint-Germain". (Según Lantier, 1935).

\section{3. "Jinete Saint-Germain"}

Otro destacado ejemplar se encuentra depositado en el Musée des Antiquités Nationales de Saint-Germain-en-Laye con el inv. $\mathrm{n}^{\circ} 77874-41$, habiendo sido publicada por Lantier $\left(1935,40, n^{\circ} 4\right.$, lám. I,4) sin indicar su procedencia, aunque posteriormente se haya atribuido a un "santuario de la provincia de Jaén" (Aranegui et alii, 1998, 147, 329, n²96), lo que debe valorarse como una referencia genérica, pues se considera que la mayoría de los exvotos depositados en dicho Museo podrían provenir de Despeñaperros, Santa Elena, Jaén (Nicolini, 1968, 30 s.).

La pieza reproduce los mismos elementos que caracterizarian al grupo (Fig. 3), como el caballero desnudo, el casco del jinete, el tocado del caballo, el soporte con las volutas y el cilindro formado por anillos, aunque presente unas dimensiones algo inferiores. El cuerpo del jinete, desnudo y en posición erguida, aparece echado hacia atrás, con los brazos en ángulo recto sosteniendo las riendas, de las que no parecen diferenciarse. Tiene una destacada nariz, algo curva, y grandes ojos almendrados. Porta un casco redondeado, con guardanuca resaltado. El penacho del casco es proporcionalmente menor que en las dos piezas anteriores, tanto en altura como en longitud, presentando una base mayor; completamente exento como el ejemplar de Cuenca, cae por detrás de la cabeza, pudiendo estar roto en su tramo final, habitualmente doblado, y que falta en esta pieza. El caballo está representado en idéntica actitud que la del ejemplar del Museo de Cuen- ca, manteniendo como éste la desproporción en relación al jinete.

La figura se levanta sobre dos pares de volutas que se apoyan sobre un soporte circular, que se alza sobre un cilindro, seguramente hueco, ensanchándose en sus extremos, presentando una moldura anular en el extremo inferior y otra más en su centro.

Dimensiones: altura: $6,5 \mathrm{~cm}$; altura del grupo ecuestre, 3,6 cm; longitud, $2 \mathrm{~cm}$.

\section{4. "Jinete de Espejo 1"}

Se trata de una pieza procedente de una colección particular de Barcelona que, al igual que la que analizaremos a continuación, ha sido donada al Gabinete de Antigüedades de la Real Academia de la Historia ${ }^{4}$. Al parecer, fue encontrada en la zona de Espejo (Córdoba). Este ejemplar ofrece idénticos elementos a los descritos en las piezas anteriores, aunque con algunas diferencias poco significativas, destacando quizás el tamaño del caballo, proporcionalmente mayor en este caso, hasta el punto de que si en aquéllas la cabeza del équido quedaba claramente por debajo de la del jinete, en esta pieza la de éste apenas sobresale por encima de aquélla (Fig. 4). Como en el "Jinete Saint-Germain", el caballero está representado echado hacia atrás, con los brazos también levantados, aunque ahora estén separados del cuerpo, reteniendo las riendas, que aparecen inclinadas hacia arriba, con una ligera curvatura, dotando al conjunto de un carácter menos estático que el que ofrecen los dos ejemplares descritos en último lugar, donde los jinetes se limitan a sostener las riendas. Las manos están realizadas con un ligero ensanchamiento de la barra que forma el brazo, observándose con mayor claridad la derecha, que parece abrirse para coger las riendas. Está tocado con un casco de forma redondeada, provisto de guardanuca y con borde resaltado, lo que le asemeja a las piezas descritas, aunque en este caso falta la cimera, por estar rota, si bien conserva el ancho soporte de la misma. Presenta nariz indicada, asi como la boca y los ojos, aunque la deficiente conservación impide observar estos detalles con mayor claridad. El

\footnotetext{
${ }^{4}$ Estas piezas formaban parte de la colección del Dr. Mariano Fernández Fairén, quien ha tenido el rasgo de generosidad de donarlas, dado su interés, a la Real Academia de la Historia, donde se conservan a partir de ahora en su Gabinete de Antigüedades.
} 

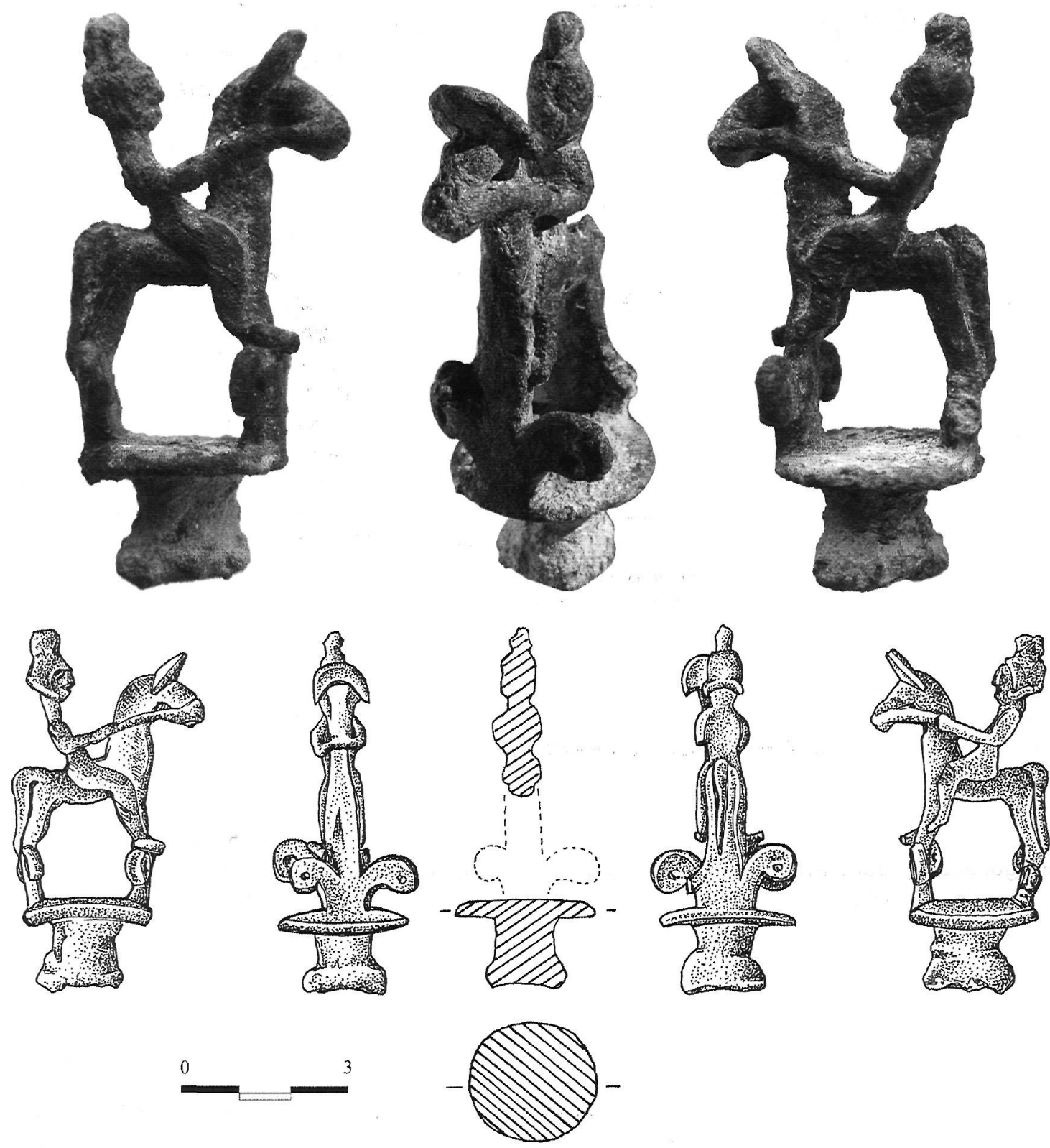

Figura 4: "Jinete de Espejo 1".

caballo lleva, asimismo, idéntico tocado que los dos ejemplares anteriores, con la característica forma de creciente, indicándose la zona de los ojos mediante un resalte.

El conjunto se levanta sobre los consabidos pares de volutas, faltando uno de los ramales traseros, al tiempo que se observa, sobre la voluta delantera derecha, los restos de una pieza filiforme que debió, originariamente, estar unida con la del lado izquierdo, donde tan sólo queda la impronta de la misma. El soporte es circular, lo que la diferencia de la pieza de Cuenca, de forma rectangular, alzándose so- bre un cilindro, macizo y mucho más corto que los anteriores por faltar la zona hueca, la más frágil, que permitiría enastar la pieza. El ejemplar está incompleto, faltándole la cimera del casco, uno de las volutas traseras y parte del vástago.

Dimensiones: altura total conservada, $6,29 \mathrm{~cm}$; altura hasta la base del soporte, $4,94 \mathrm{~cm}$; altura conservada del cilindro, $1,18 \mathrm{~cm}$; anchura máxima (volutas), 2,28 cm; longitud máxima (caballo), 3,05 cm; diámetro de la base, $2,3 \mathrm{~cm}$; grosor de la base, $0,33 \mathrm{~cm}$; diámetro del cilindro, 1,23-1,51 cm; peso, 44,3 gr. 
Análisis metalográfico (PA11821) ${ }^{5}$ : Cu: 78,8 \%; $\mathrm{Sn}: 6,44 \%$; Pb: 13,7\%; Fe: 0,89\%; Ni: nd; Zn: nd; As: nd; Ag: 0,062 \%; Sb: 0,139\%.

\section{5. "Jinete de Espejo 2"}

En la citada colección se conservaba un segundo ejemplar, actualmente en el Gabinete de Antigüedades de la Real Academia de la Historia, de iconografía relacionada con las piezas descritas, aunque su factura resulta mucho menos cuidada, faltando, asimismo, algunos de los elementos característicos de este tipo de piezas, como el soporte de volutas (Fig. 5). Al parecer, tendría una procedencia similar a la pieza anterior.

El jinete, desnudo, aparece inclinado claramente hacia atrás, lo que le asemeja con el otro ejemplar descontextualizado y con la pieza del Museo de Saint-Germain-en-Laye, aunque, a diferencia de los ejemplares analizados, presenta las piernas rectas, con los pies bien representados, indicando incluso el talón, ocupando una posición algo más alta que en los restantes ejemplos. Porta las riendas con ambas manos, extendidas y oblicuas, con un sogueado en la zona de unión entre unas y otras. Presenta un tratamiento muy esquemático de la cara, desproporcionada respecto al resto del cuerpo, representándose los ojos, nariz y boca entreabierta. El casco corresponde al modelo descrito y en él se observan restos del guardanuca en el lado izquierdo, con el penacho pegado al capacete, faltando el soporte documentado en las otras piezas estudiadas. A diferencia de éstas, se observa en los laterales del capacete lo que parecen ser sendos roleos, uno a cada lado, bien documentados en los modelos escultóricos sobre piedra de Porcuna, Jaén (Negueruela, 1990, figs. 4 bis, $5,18 \mathrm{~A}, 18 \mathrm{~B}, 19$, láms. VA y $\mathrm{B}, \mathrm{VII}-\mathrm{IX}, \mathrm{XV}-\mathrm{XVI}$, $X L I I)$, que, como veremos, constituyen el paralelo más cercano de los ejemplares citados, aunque también pudiera tratarse de los elementos posiblemente metálicos que se añadirian a los laterales de estos cascos, según confirman las incisiones presentes, también, en Porcuna (Fig. 7) (Negueruela, 1990, 131 s.).

El caballo tiene las patas abiertas y algo curvadas, en posición oblicua, por lo que parece estar en actitud de frenado. La cola, ligeramente arqueada, cae entre las patas del animal, aunque claramente separada de ellas. Está representado el sexo del animal, siendo la única pieza que ofrece este detalle. Igualmente, se han reproducido las orejas, puntiagudas, así como los ojos, tan sólo insinuados, y la boca, entreabierta, dada la presencia del bocado. Sobre la frente, un tocado rectangular adornaría la frontalera.

La figura se levanta sobre una placa de tendencia rectangular, algo irregular en su grosor, que, a su vez, se alza sobre un vástago macizo de sección circular de gran longitud, fracturado en su extremo, lo que diferencia a esta pieza del resto de los ejemplares estudiados, que presentan soportes tubulares huecos. Así, mientras que estos ejemplares irían fijados a un astil de madera, en el caso de la pieza de Espejo 2, tanto la figura del jinete como el vástago sobre el que se alza estarían realizados en una sola pieza broncínea.

Dimensiones: altura total, $12,44 \mathrm{~cm}$; altura hasta la base del soporte, $7,24 \mathrm{~cm}$; longitud conservada del vástago, $5,73 \mathrm{~cm}$; anchura máxima (pies del jinete), $2,16 \mathrm{~cm}$; longitud máxima (caballo), $5,05 \mathrm{~cm}$; dimensiones de la base, $3,14 \times 1,34 \mathrm{~cm}$; grosor de la base, $0,39 \mathrm{~cm}$; diámetro del vástago, $1,1 \mathrm{~cm}$; peso, $112,45 \mathrm{gr}$. Análisis metalográfico:

(PA11822a) (vástago): Cu: 94,0\%; Sn: 1,82 ; Pb: 2,71\%; Fe: 0,92 \%; Ni: nd; Zn: nd; As: nd; Ag: $0,071 \%$; Sb: 0,545\%.

(PA11822b) (casco): Cu: 93,7\%; Sn: 2,49; Pb: 2,55 \%; Fe: 0,61 \%; Ni: nd; Zn: nd; As: nd; Ag: 0,101\%; Sb: 0,555\%.

\section{PARALELOS Y CRONOLOGÍA}

Todas estas piezas "tipo La Bastida", por su tipología y función, constituyen un grupo muy homogéneo de bronces ibéricos. Su elemento más significativo es el jinete, tanto para determinar la cronología de la pieza como su función y significado, en el que destaca sin lugar a dudas el casco. Éste ofrece la calota de forma redondeada con un grueso reborde que ha hecho pensar que se trata de cascos de cuero; la apertura de la cara es cuadrada, aunque en el ejemplar de La Bastida parece adaptarse al contorno de los ojos, dada la ausencia de reborde en la zona frontal de la pieza, y están rematados en los mejores ejemplares por un penacho que puede alcanzar proporciones exageradas. Este tipo de casco, que resulta característico de este conjunto de piezas de bronce,

\footnotetext{
${ }^{5}$ La composición de los objetos ha sido obtenida mediante análisis por espectometria de fluorescencia de rayos $\mathrm{X}$ en dispersión de energías.
} 

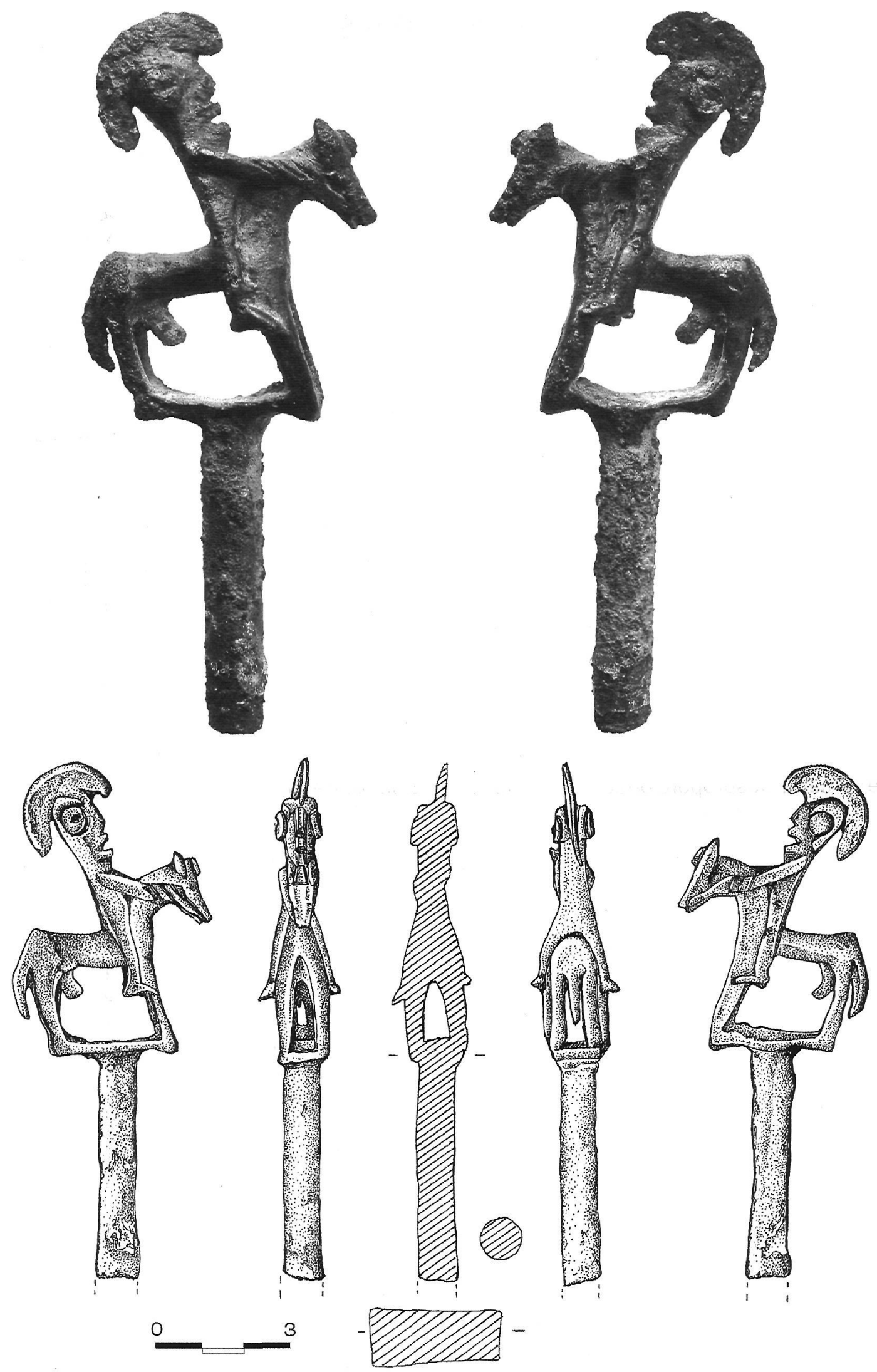

Figura 5: "Jinete de Espejo 2". 
también se documenta en alguna otra rara figurilla de guerrero ibérica, como las procedentes del Collado de los Jardines, Santa Elena, Jaén (Álvarez-Ossorio, 1941, lám. 37, nº 29 y 31; Nicolini, 1968, 120, $\mathrm{n}^{\circ} 1$ y 2; AlmagroGorbea y Fernández-Miranda (eds.), 1983, 64; Aranegui et alii, 1998, 325, $\mathrm{n}^{\circ}$ 281). Igualmente, llevan este tipo de casco los jinetes de algunos pequeños bronces ibéricos, pero generalmente ya sin cimera (Álvarez-Ossorio, 1941, lám. 77-79), alguno de los cuales, a juzgar por su tamaño, su desnudez y la disposición de las patas del caballo (Fig. 6) (Álvarez-Ossorio, 1941, 96, $n^{\circ} 593$; igualmente, $n^{\circ} 422$; vid. Prados, $1992, n^{\circ} 426$ y 422 , respectivamente), quizás se pudiera incluir en este grupo del "Jinete de La Bastida" si se supone que, como esta última pieza, hubieran perdido su soporte.

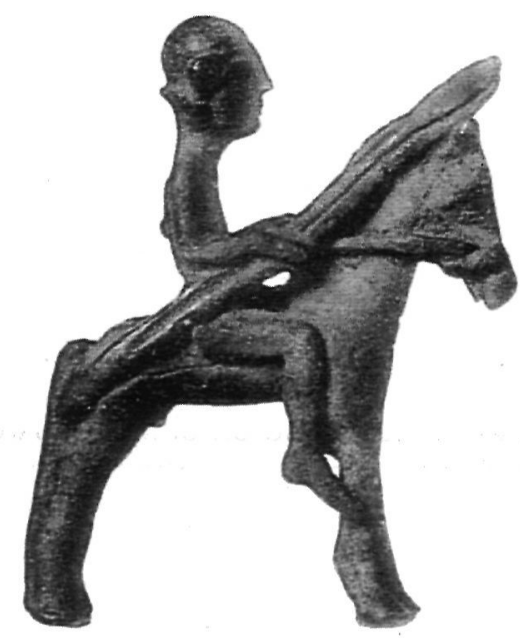

Figura 6: Jinete del Collado de los Jardines (Jaén). (Según Álvarez-Ossorio, 1941).

Sin embargo, la mejor documentación de este tipo de casco tan característico es la que ofrecen los guerreros principales del conjunto escultórico del herôon de Porcuna, Jaén, que ha proporcionado fragmentos de tres ejemplares (Fig. 7) de características similares al analizado (Negueruela, 1990, figs. 4, 5,18A, 18B, 19, lám. I-IX, XV-XVI, XLII, XLIIIA-B). En su estudio del jinete de La Bastida, Kukahn (1954, nota 25) consideró que el tipo se puede clasificar como un "casco de caballero griego de origen mediterráneo oriental, que desde el siglo VI se encuentra sólo en gran número entre los pueblos de la Grecia septentrional", señalando la ausencia de ejemplares reales conservados con los que establecer paralelos. Por su parte, tanto Blanco (1987, 418 ss.) como Negueruela (1990, 135 ss., lám. XLIII, bis) defienden un origen mediterráneo oriental, quizás jonio, aunque falten algunos de los elementos que caracterizan el modelo, como las carrilleras móviles, lo que lleva a Negueruela (1990, $136 \mathrm{~s}$.) a considerar que los cascos de Porcuna responden a un tipo propio, que ya no puede definirse como casco jonio aun aceptando la relación entre ambos modelos, por lo que deben denominarse como cascos "jonio-ibéricos". Para este autor (Negueruela, 1990, 131, 138), la ausencia de piezas reales se debería a su carácter excepcional, proponiendo que fueran enteramente metálicos, aunque no se pueda descartar que más bien se trate de un tipo de estructura mixta de cuero y metal (Quesada, 1997, 565).

La evidente similitud entre el tipo de casco representado en Porcuna y el que porta el jinete de La Bastida ha sido insistentemente traída a colación (Blanco, 1987, 422; Negueruela, 1990, 138; Quesada, 1997, 565), si bien, como ha señalado Negueruela (1990, 138), existen algunas diferencias entre ellos, como la ausencia de reborde en el enmarque de la cara, que quedaría limitado a la zona de la nuca, o el hecho de que la cimera no se adose al casco, quedando suspendida en alto por un soporte, lo que quizás sea debido a la dificultad de talla de este elemento en los ejemplares esculpidos, detalle éste último que cabe hacer extensible a las restantes piezas, muy similares al ejemplar valenciano.

Los paralelos más próximos de los cascos de Porcuna son anteriores al 480 a.C. (Negueruela, 1990, 137, lám. XLIII,bis), fecha comúnmente aceptada para este conjunto escultórico (Almagro-Gorbea, 1996, 64 s.; id., $1999,16)$. Una cronología similar ya fue sugerida por Kukahn $(1954,150)$ para el ejemplar de La Bastida, toda vez que la pieza resulta "más comparable con representaciones del mismo género pertenecientes al fin de la época arcaica o ya a comienzos del siglo $\mathrm{V}$ a.C.", aunque el contexto general del poblado de La Bastida le llevase a aceptar una fecha más avanzada, "entre el fin del siglo $\mathrm{V}$ hasta el IV" (Kukahn, 1954, 157). Sin embargo, el "Jinete de La Bastida" ofrece un detalle estilístico propio de un taller jonio-ibérico bien identificado, como es el rizo ondulado del flequillo del caballo que cae sobre su cuello, un elemento estilístico característico de los mejores bronces y esculturas jonio-ibéricas del final del Arcaísmo (Almagro-Gorbea et al., 2004, 228 s., $n^{\circ} 413$ ), lo que confirma su cronología no posterior al 460-450 a.C. 

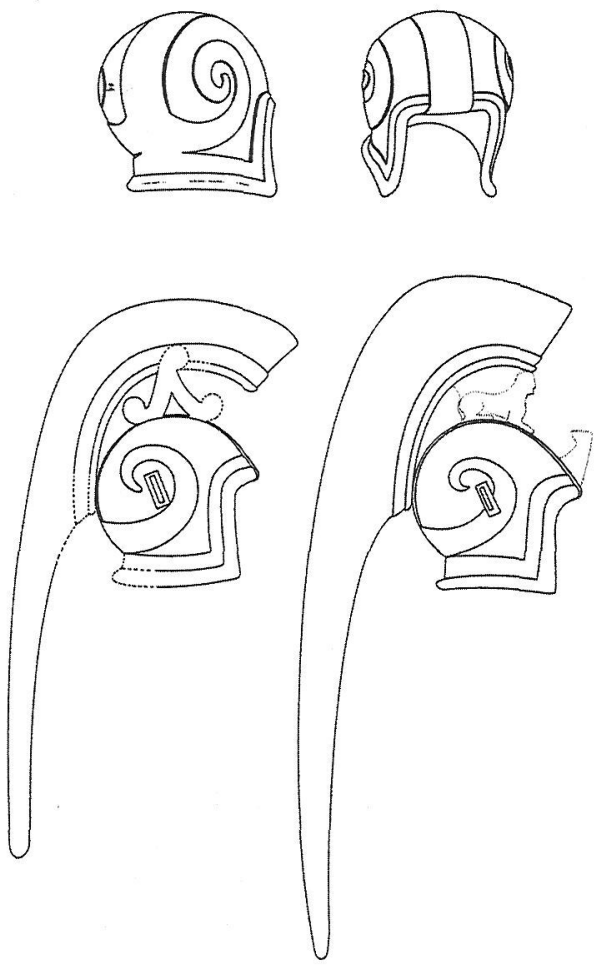

Figura 7: Reconstrucción de los cascos del Cerrillo Blanco de Porcuna (Jaén). (Según Negueruela, 1990).

Algo más moderno se ha considerado el casco que porta un fragmento escultórico de La Alcudia de Elche, Alicante, de forma redondeada, con guardanuca y sin resto de cimera, pero su fuerte erosión impide apreciar sus detalles (Ramos Molina, 2000, 12 s., lám. III; Lorrio, 2004, 161). La pieza, según Quesada $(1997,566)$, sería similar al modelo representado en Porcuna, aunque simplificado por la presencia de guardanuca y borde resaltado. Esta pieza, junto a las restantes esculturas de guerrero de este yacimiento, integrarian uno o varios grupos escultóricos de heroa, que cabría situar entre mediados del siglo $\mathrm{V}$ hasta el IV a.C. (Almagro-Gorbea, 1999, 13).

Otro elemento muy significativo de estas piezas es la presencia de sendos pares de volutas entre cada una de las cuales se apoyan las patas del caballo, elementos que se deben interpretar como "capiteles protoeólicos". El origen fenicio-palestino de este tipo de capitel está bien documentado (Betancourt, 1977; Shiloh, 1979; Akurgal, 2000, 53 s.) y llegó a extenderse por Occidente, como evidencian algunos de los anillos aúreos del tesoro de Aliseda (Almagro-Gorbea, 1977, láms. XXXI$X X X I I)$ o la conocida pieza realizada en piedra caliza del Museo de Cádiz (Blázquez, 1975, 167 s., lám. 63) que, a juzgar por su pequeño ta- maño, probablemente constituía el remate del soporte de alguna figura dedicada como exvoto en el santuario gaditano, por lo que, dada su cronología, hacia el siglo VII a.C., no puede descartarse su relación con el prototipo teórico de estas piezas de bronce. Pero los capiteles protoeólicos fueron pronto asimilados por los artistas jonios (Akurgal, 1969, 226 s.; id., 2000, $53 \mathrm{~s}$.), por lo que esta idea, en estos pequeños bronces, pudiera perfectamente proceder de dicho ámbito colonial, ya con una cronología de la primera mitad del siglo $\mathrm{V}$ a.C. (Moneo, $2004,4,375$ ). Así lo confirma la presencia de un posible fragmento perteneciente a uno de estos elementos arquitectónicos en el ya citado monumento de Porcuna (Negueruela, 1990, 275, fig. 36 y lám. LII,A). Efectivamente, las piezas broncíneas representan una gran hoja en voluta a cada lado, preceptiva del modelo y su rasgo más identificador formalmente (Negueruela, 1990, 275); en cambio, faltan las menores que surgen junto a aquélla, pudiendo considerar, finalmente, al vástago de enmangue como la representación del árbol del que nacen las referidas hojas.

Pero el mejor paralelo de estas parejas de volutas contrapuestas tan características aparece en otro pequeño bronce ibérico. Se trata del "Guerrero sacrificando un carnero sobre las aguas" conservado en el Museo Arqueológico Nacional (Almagro-Gorbea y FernándezMiranda (eds.), 1983, 148, n 107; Olmos (ed.), 1992, 146 s.; Moneo, 2004, 375, fig. VI,8, $n^{\circ} 1$ y portada), que ofrece este peculiar detalle que confirma la cronología y la adscripción tipológica señaladas. Dicho guerrero es una obra maestra entre los pequeños bronces ibéricos, y los rizos ondulados de su peinado confirman su pertenencia a un taller jonio-ibérico recientemente identificado y que, al parecer, trabajó en el santuario del Collado de los Jardines hacia el 475-450 a.C. (Almagro-Gorbea et al., 2004, 229-230).

Característicos de estos bronces son también los tocados en forma de creciente que lucen los caballos sobre la frente, a modo de visera, elemento identificado en tres de las piezas estudiadas $\left(n^{\circ} 2,3\right.$ y 4 ), y que resulta bastante raro entre las figuritas broncíneas de jinete, documentándose en el "Jinete de EI Salobral”, Albacete (Nicolini, 1969, 59, pl. I,3), o en dos ejemplares del santuario del Collado de los Jardines, Jaén (Alvárez-Ossorio, 1941, 97$98, n^{\circ} 598$-M.A.N. 29332-, 99, n 606 -M.A.N. 29329-; Nicolini, 1969, n. 2, fig. 1), identificándose, asimismo, en piezas orientalizantes, 
como el conocido caballo, igualmente de bronce, de Cancho Roano, Badajoz (Celestino y Zulueta, 2003, 52-55, fig. 16.1, lám. X.3-4), pudiendo haberse representado, también, en la figura de jinete reproducida en una sortija con sello de oro del tesoro de Aliseda, Cáceres (Almagro-Gorbea, 1977, lám. XXX,2 y 4). Por lo que se refiere a las otras dos piezas, aun careciendo de este detalle ornamental se observan igualmente otros elementos decorativos, igualmente localizados sobre la frente del animal. Este es el caso de la frontalera decorada de la pieza de Espejo 2 ( $n^{\circ} 5$ ), similar a la que luce una escultura de caballo de El Cigarralero, Mula, Murcia (Tarradell, 1968, fig. 94), o del peinado del caballo de La Bastida ( $n^{\circ} 1$ ), que constituye un recurso estilístico igualmente documentado en piezas como una figura broncínea de caballo procedente de Despeñaperros, Jaén (Nicolini, 1973, 75, $n^{\circ} 45$ ) o la magnífica cabeza de équido igualmente de El Cigarralero (Quesada y Zamora (eds.), 2003, portada).

\section{PROCEDENCIA Y CONTEXTO CULTURAL}

Por desgracia, se desconoce el lugar del hallazgo y el contexto arqueológico de la mayor parte de estos bronces ibéricos, a excepción del "Jinete de La Bastida", pues sólo hay noticias al respecto sobre el "Jinete del Museo de Cuenca" y, con serias dudas, del conservado en el Museo de Saint-Germain-en-Laye.

El primero procede del poblado ibérico de La Bastida de les Alcuses, Mogente, que se considera construido a finales del siglo $\mathrm{V}$, o inicios del IV a.C., siendo incendiado y abandonado tras apenas un siglo de existencia (Bonet et al., 1997, 270 ss.; Bonet, 2001, 71), lo que lleva a precisar su cronologia a lo largo del siglo IV a.C.

El "Jinete" se halló en el departamento 218, que formaria parte de la llamada "Casa 10" (Fig. 8), un edificio singular para el que Díes y Álvarez (1998) han sugerido una posible función palacial, pues se trata de una construcción de $326 \mathrm{~m}^{2}$ delimitada por una plaza situada en prolongación de la calle principal, al Norte, el camino de ronda, al Sur, y por dos calles transversales en los lados menores. El edificio estaba integrado por 14 departamentos, con un cuerpo central, al que se accederia desde la plaza, con diversas habitaciones intercomunicadas entre sí y otras localizadas en los lados noroeste y este, abiertas al exterior (Díes Cusi y Álvarez Garcia, 1998, 333 y 335). La zona central, donde se localiza el departamen- to 218 , y las habitaciones del ángulo noroeste parecen corresponder a una primera fase constructiva, mientras que las de la zona este o las del sur, situadas a un nivel inferior y abiertas al camino de ronda, corresponderían a un segundo momento (Díes Cusí y Álvarez García, 1998, fig. 3). Ante la casa estaba la cisterna del poblado, que aprovechaba una grieta natural del terreno. El departamento 218 formaba parte del cuerpo central del edificio, siendo la más interesante de las estancias localizadas en esta zona. Era una habitación cuadrangular de reducidas dimensiones $(4 \times 1,8 \mathrm{~m})$, a la que se accedía a través de un pasillo. Por el diario de excavación se sabe que la figurilla de jinete apareció a $45 \mathrm{~cm}$ de profundidad junto a la pared oeste (Fig. 8) (Ballester, 1931, 47 s.), describiéndose, igualmente, algunas de las piezas recuperadas en la " $3^{a}$ capa", un nivel muy compacto formado por el derrumbe de los adobes y los restos de los suelos de tierra apisonada (Fletcher et al., 1965, 21, fig. 5; Díes Cusí y Álvarez García, 1998, 331). La relación incluye (Ballester, 1931, 49 s.; vid., igualmente, los inventarios) una botella en miniatura (de 6,4 cm de altura) "de barro pintado a torno", de corto borde cóncavo, cuerpo bitroncocónico y base anular umbilicada; 4 fusayolas, 2 troncocónicas y 2 bitroncocónicas; un anillo de fíbula anular, decorado con cinco haces de tres líneas incisas paralelas, dispuestos de forma equidistante, en el que se conservan, posiblemente, los restos del inicio del puente y del resorte ( $N^{\circ}$ inv. 1.069); un ponderal cilíndrico de plomo ( $\mathrm{N}^{\circ}$ inv. 2.102) $(d=2,2 \mathrm{~cm} ; \mathrm{h}=0,83 \mathrm{~cm}$; peso=29,8 $\mathrm{gr})$; fragmentos de tres conchas bivalvas; así como un objeto en forma de $U$ estrangulada y con los extremos vueltos, un regatón, un gancho y un objeto macizo de forma cónica, todos ellos de hierro, señalándose, además, la presencia de cerámica en la $2^{a}$ y $3^{a}$ capa (Ballester, 1931, $54)^{6}$. Aunque el hallazgo del regatón pudiera

\footnotetext{
${ }^{6}$ Con la excepción de la figura de jinete, se trata de objetos presentes, en general, en otros departamentos del poblado. Así ocurre con los microvasos -Grupo IV de Mata y Bonet (1992, 134-135, fig. 16)-, documentándose uno muy similar, aunque sin decoración, en el departamento 3 (Fletcher ef al., $1965,40,2)$, los ponderales, presentes en diversos departamentos (Fletcher y Mata, 1981, 171 ss.), al igual que las fusayolas, las conchas, las piezas de extremos vueltos, descritas como chavetas, o los regatones (vid., para todos ellos, Fletcher et al., 1965; id., 1969), encontrándose también ejemplos de las restantes piezas de hierro (Fletcher et al., 1965, $174,1 ; i d ., 1969,126,29$ y 198,11$)$. Por lo que se refiere al anillo, de $3,4 \mathrm{~cm}$ de diámetro y 0,45 de grosor, se ha interpretado como parte de una fíbula anular hipánica, tipo 4 de Cuadrado, bien documentado en el poblado y del que se conocen algunos ejemplos con anillos igualmente decorados con líneas incisas formando grupos equidistantes (Fletcher et al., 1965, 46,10,178,16; /d., 1969, 173,32).
} 


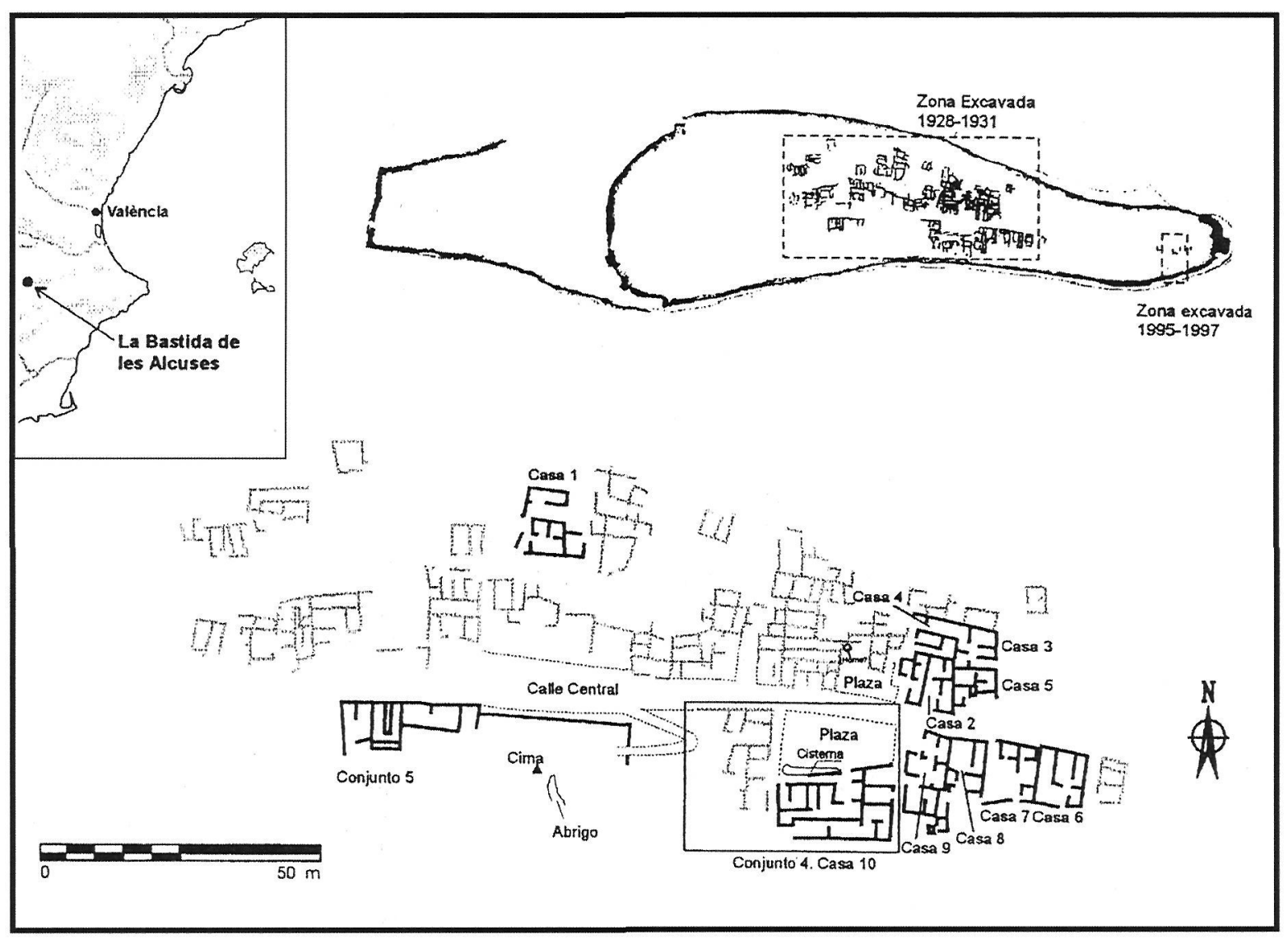

Plaza

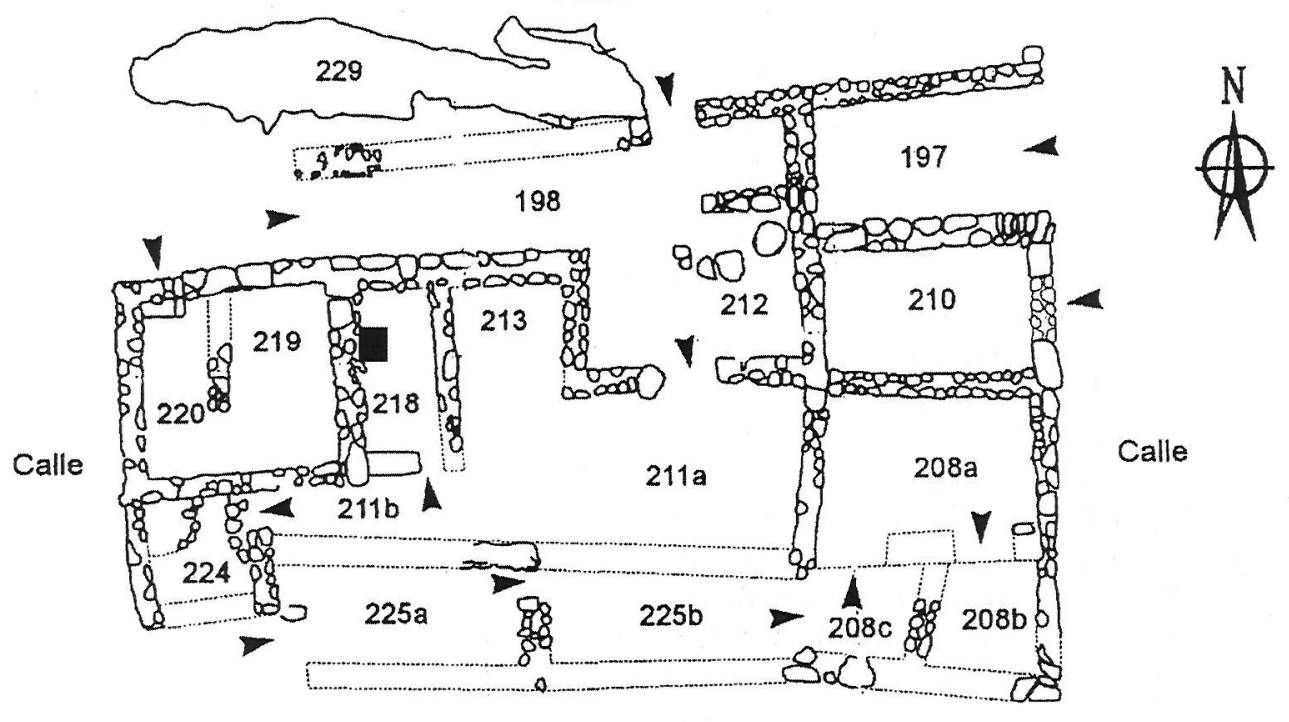

Camino de ronda

Figura 8: Planimetría del poblado de La Bastida de les Alcuses, con indicación de la localización de la Casa 10 (arriba) y planta de dicho edificio con la denominación de los departamentos (abajo) y el lugar donde apareció la figurilla de jinete ( $\mathbf{\square}$ ). (A-B, según Díes Cusí y Álvarez García, 1998; identificación del lugar del hallazgo, según Ballester, 1931). 
relacionarse con el que pudiera haber tenido originariamente el "Jinete", como se documenta con los signa equitum de Numancia (Almagro-Gorbea y Torres, 1999, 96 s.), el hecho de que no se recuperara elemento alguno relacionado con el soporte de la pieza, sugiere que ésta, en el momento del abandono del poblado, pudiera llevar algún tiempo rota, por lo que no sería necesario el uso del regatón, elemento, en cualquier caso, habitual en los diversos departamentos excavados en La Bastida (Fletcher et al., 1965, 30,20, 130,18, 160,42, etc.; id., 1969, 28,9-10, 53,8, 85,49-51, etc.).

La gran superficie del edificio, que, tras su reforma, habría multiplicado el tamaño medio de las casas de La Bastida, su ubicación singularizada y con una orientación favorable, ocupando un espacio relativamente central dentro de la trama urbana, su asociación con la única cisterna del poblado, la identificación del espacio destinado para albergar el carro, lo que implicaría su posesión como símbolo de estatus (Fernández-Miranda y Olmos, 1986, 160 s.; Almagro-Gorbea et al., 2004, 228) y el hallazgo de materiales destacados, entre los que sobresale el conocido "Jinete", son argumentos que, con acierto, han llevado a Díes y Álvarez (1998, 336 ss.) a considerar la Casa 10 como un edificio que podría haber ejercido la función palacial dentro del poblado. En consecuencia, debe considerarse como una vivienda de elite, seguramente la residencia de quien ejercería la jefatura del poblado, aparentemente un monarca, dado su carácter tan destacado, prácticamente único, en la población. En todo caso, el material recuperado en el departamento 218 permite descartar con seguridad que el edificio pudiera considerarse como un lugar de culto y que el jinete pudiera haber sido un exvoto (Díes Cusí y Álvarez García, 1998, 334), aunque Moneo $(2004,173)$ ha señalado que la habitación donde apareció el "Jinete" pudiera considerarse como el santuario o el espacio destinado a guardar los sacra gentilicia relacionados con el culto familiar, siendo evidencia de ello el hallazgo de dicha figurita de bronce.

El "Jinete del Museo de Cuenca" procede de La Manchuela conquense (vid. supra, $\S$ 1), comarca localizada en el Sureste de esa provincia, posiblemente, según noticias sin confirmar, de la zona de Castillejo de Iniesta, localidad que ocupa una posición central dentro del extenso territorio que se extiende por el interfluvio que forman el río Júcar en su tramo medio y su afluente el Cabriel. El interés de la zona durante la Edad del Hierro era conocido gracias a diferentes trabajos de excavación y a algunos hallazgos aislados localizados en la margen izquierda del Júcar, hacia el noreste de la comarca, como el poblado de Fuente de la Mota, en Barchín del Hoyo (Sierra, 1981; id., 2002; id., 2003), y las necrópolis de Buenache de Alarcón (Losada, 1966) y Olmedilla de Alarcón (Almagro-Gorbea, 1976-78, figs. 2325 ), aunque las excavaciones llevadas a cabo en los últimos años en las necrópolis de la Punta de Barrionuevo (Valero, 1999) y de Cerro Gil (tríptico del Museo Arqueológico de Iniesta), en el termino municipal de Iniesta, de las que tan sólo contamos con algunos avances, han venido a confirmar la importancia de este territorio en época ibérica. Los materiales recuperados en todos estos yacimientos avalan la existencia de importantes contactos con el Sureste y el Levante, seguramente a través de los llanos de Utiel y Requena (Almagro-Gorbea, 1976-78, 138), como cerámicas áticas o de barniz rojo, así como determinados tipos de fíbulas o las estructuras tumulares localizadas en Iniesta (Valero, 1999). La vinculación al ámbito ibérico de Iniesta no parece ofrecer dudas, como lo confirma la reciente ubicación en dicha localidad de la ceca ibérica de ikalesken (Ripollès, 1999), sin olvidar la presencia de influjos célticos, como indica el hallazgo, formando parte del mismo decomiso y procedente de esta misma zona, de un plomo en lengua celtibérica (Lorrio y Velaza, e.p.), el más meridional de los documentos epigráficos celtibéricos documentados hasta la fecha, elementos todos ellos de cronología más moderna que la defendida para la figurita de jinete. En lo que se refiere al contexto, los hallazgos que formaban el decomiso parecen proceder tanto de poblados como de necrópolis, aunque el jinete pudiera haber sido hallado en una necrópolis asociada a un poblado de la zona.

Por su parte, el "Jinete Saint-Germain" (Lantier, 1935, 40, $\mathrm{n}^{\circ} 4$, lám. I,4) se ha publicado como procedente de un "santuario de la provincia de Jaén" (Aranegui et alii, 1998, 329, n 296), lo que resulta verosímil a juzgar por su estilo, aunque esto pudiera deberse al tópico de atribuir todos los bronces ibéricos a los conocidos santuarios jienenses de Sierra Morena (Nicoloni, 1969, 31), por lo que carecería de procedencia y contexto, debiendo, pues, considerarla con cierta precaución.

Finalmente, no existe noticia alguna sobre el contexto de las dos piezas halladas supuestamente en la provincia de Córdoba, aun- 
que las referencias a su procedencia de Espejo no ofrecen motivos que induzcan a la duda.

\section{FUNCIÓN Y SIGNIFICADO}

El elemento funcional más característico de todas estas piezas es un vástago de enmangue, lo que permite diferenciarlas de otras figurillas broncíneas, generalmente inter- pretadas como exvotos dado su hallazgo habitual en santuarios. Aunque la pieza del Museo de Saint-Germain, supuestamente procedente de un santuario, ha sido interpretada como un portarriendas (Lantier, 1935, 40; Aranegui et alii, $1998,329, n^{\circ} 296$ ), dicha interpretación carece de fundamento. En efecto, el citado vástago permite plantear como interpretación más probable que se trata de signa equitum ibéricos (Fig. 9), dada su semejanza con un conjunto
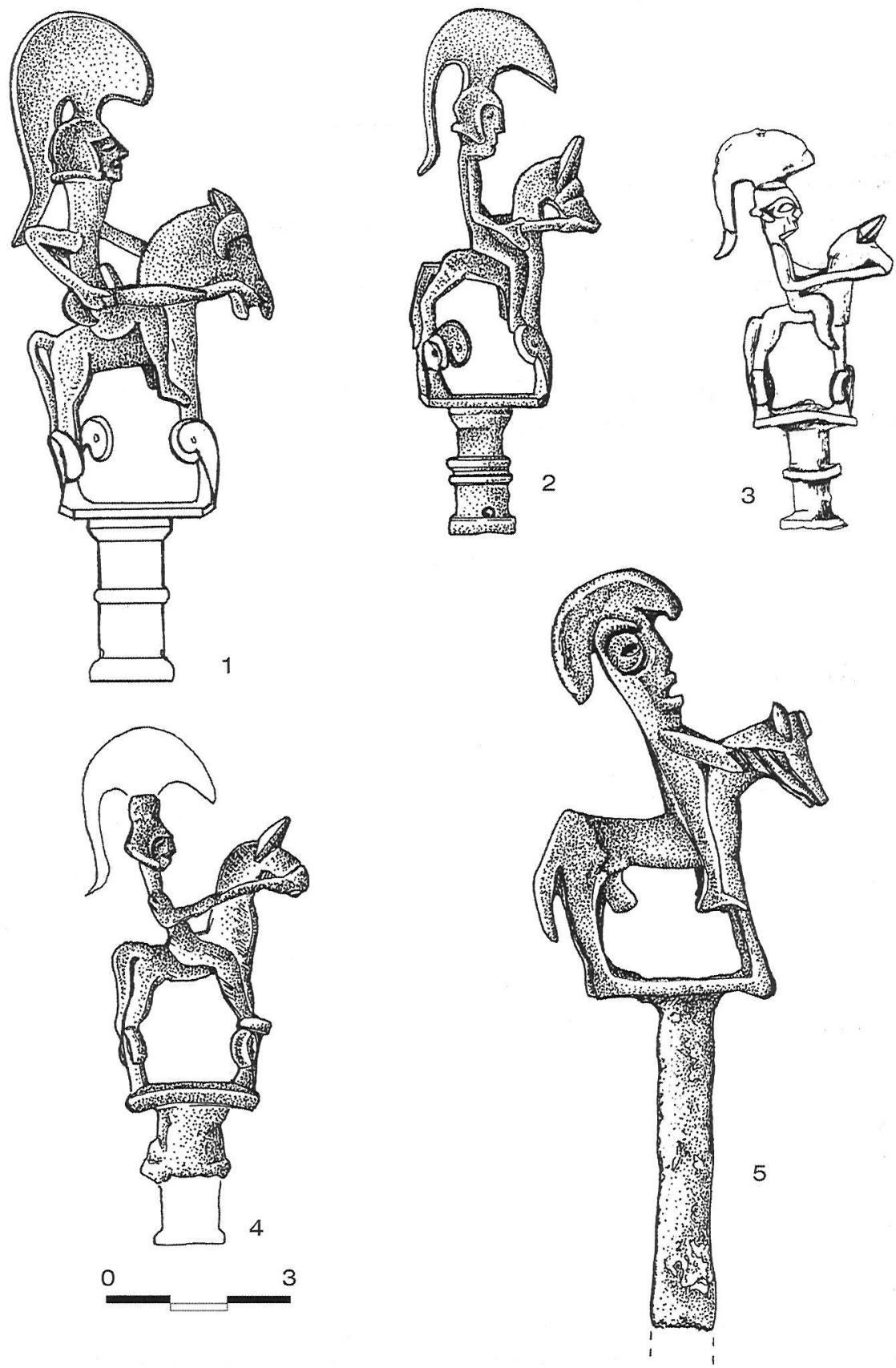

Figura 9: Signa equitum ibéricos: 1, "Jinete de La Bastida" (propuesta de reconstrucción); 2, "Jinete del Museo de Cuenca" (completado); 3, “Jinete Saint-Germain”; 4, "Jinete de Espejo 1" (propuesta de reconstrucción); 5, "Jinete de Espejo 2". 


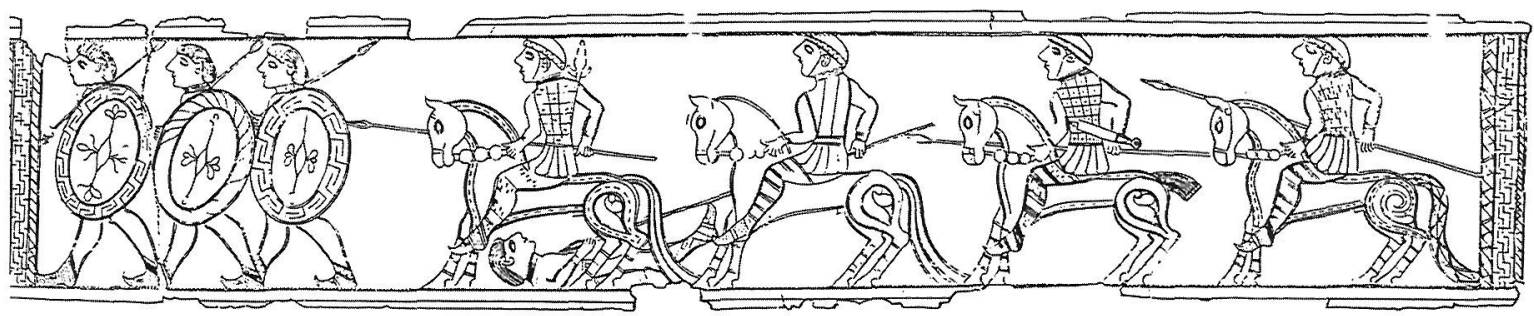

Figura 10: Detalle del motivo central de la vaina decorada de la tumba 994 de Hallstatt en la que el jinete que encabeza la comitiva porta un estandarte sobre el hombro. (Según Frey, 1991).

de piezas broncíneas celtibéricas así interpretadas (Lorrio, 1997, 198; Almagro-Gorbea, 1998; Pastor Eixarch, 1998; Almagro-Gorbea y Torres, 1999, 96 s.).

Se trata de tres ejemplares procedentes de Numancia, uno de ellos aparecido en la ciudad (Schulten, 1931, 271, lám. 44B) y los otros dos en la necrópolis, formando parte del ajuar de la tumba 38 (Jimeno, 1994, lám 48; id., 1996, 61 , fig. 4). Son piezas de enmangue tubular rematadas por dos prótomos de caballo contrapuestos, bajo cuyos hocicos aparece una cabeza humana esquemática, que en el caso de los hallazgos de la necrópolis incorporan un jinete. Las piezas habían sido interpretadas como pasarriendas de carro (Camón, 1954, fig. 741) o, más probablemente, como insignias o cetros (Schulten, 1931, 271), estandartes (Mélida et al., 1924, 30), báculos de distinción (Jimeno et al., 2002, 58, 69, figs. 49, 52 y 54), o como remates de insignias o estandartes (Lorrio, 1997, 198), concretamente de caballería, destacando su similitud con las fíbulas hispano-célticas de jinete y de caballito (AlmagroGorbea y Torres, 1999, 97), hipótesis que concuerdan mejor, desde un punto de vista estrictamente estructural, con la asociación de las piezas a regatones. En concreto, el ejemplar procedente de las antiguas excavaciones en la ciudad apareció todavía ensartado en un astil de $1,50 \mathrm{~m}$, del que quedaban restos de madera (Mélida et al., 1924, 30, lám. 8,1).

Estos ejemplares celtibéricos presentan un tamaño ligeramente mayor que los ibéricos, entre 10,6 y $12,3 \mathrm{~cm}$, y su cronología remite a un contexto claramente posterior al de las piezas ibéricas, pues se deben fechar en el siglo II a.C., en cualquier caso con anterioridad al 133 a.C. (Jimeno et al., 2002, 69), mejor que hacia inicios del I a.C. como se ha supuesto para el ejemplar hallado en la ciudad (AlmagroGorbea y Torres, 1999, 97).

La interpretación de las piezas celtibéricas como signa equitum confirmaría, de acuerdo con Almagro-Gorbea y Torres (1999,
96 ss., 109), la importancia real de la caballería y de las elites ecuestres entre los celtíberos, de las que serían, al igual que los referidos modelos de fíbulas, distintivo de elite social, símbolo de la pertenencia a la clase de los equites. Como uno de estos estandartes podría interpretarse el objeto representado sobre el hombro del caballero que encabeza el cortejo de jinetes representados en la famosa funda de espada de la tumba 994 de Hallstatt (Fig. $10)$, fechada hacia la segunda mitad del siglo $\checkmark$ a.C. (Frey, 1991, 131), y por lo tanto contemporánea aproximadamente a estas piezas ibéricas.

Este carácter de elite se ha atribuido, asimismo, a las relativamente raras figurillas broncíneas ibéricas de jinete (Almagro-Gorbea y Torres, 1999, 89), cuyos conjuntos más numerosos proceden de algunos santuarios murcianos y andaluces (Nicolini, 1969, 59 ss.), como el Collado de los Jardines, Jaén (ÁlvarezOssorio, 1941, n 593-611), o el Santuario de La Luz, Murcia (Mergelina, 1926; ÁlvarezOssorio, 1941, $\mathrm{n}^{\circ} 1778$ ), lo que confirma una dispersión similar a la de una serie de elementos ilustrativos de la existencia aristocrática ecuestre, como los grupos ecuestres funerarios (Blánquez, 1997), los bajorrelieves con el esquema del despotes hippôn o los santuarios ecuestres, proponiendo los autores su relación, al menos para las piezas de Sierra Morena, con ritos de iniciación (Almagro-Gorbea y Torres, 1999, 89; Moneo, 2004, 393 ss.).

La aparición de aristocracias guerreras de tipo heroico tendría como consecuencia y correlato la generalización del caballo como elemento de estatus (Almagro-Gorbea, 1996, 82 ss.; Almagro-Gorbea y Torres, 1999, 87 ss.), lo que explicaría que desde entonces los caballos y jinetes sean relativamente frecuentes en la escultura ibérica, integrados por lo general en monumentos sepulcrales de carácter heroico, mientras que de forma paralela hacen su aparición los arneses de caballo en los ajuares funerarios como elemento de estatus (Chapa, 
1980, 852 s.; Almagro-Gorbea, 1983, 245; id., 1996, 119; Blánquez, 1997). En este sentido, resulta significativo que en las diversas escenas de lucha reproducidas en el herôon de Porcuna (Negueruela, 1990, 88), conjunto en el que las figurilias analizadas encuentran sus mejores paralelos, al menos en lo que respecta al tipo de casco usado, el jinete represente en todos los casos al vencedor, quien, según Almagro-Gorbea y Torres $(1999,88)$, seria un heros equitans que combate y vence a sus enemigos a pie. Jinetes, ahora montados, están igualmente representados en sendos monumentos de la necrópolis de Los Villares, Hoya Gonzalo, Albacete, fechados hacia el 475-425 a.C. (Blánquez, 1995, 76), o en el jinete de Córdoba (Chapa, 1985, lám. 20), posiblemente de la segunda mitad del siglo $V$ a.C., mientras que el héroe aparecía probablemente a pie cogiendo de la rienda al caballo en la magnífica escultura de Casas de Juan Núñez, Albacete (Blech et al., 2001, lám. 218), fechable hacia mediados del siglo $V$ a.C, y en la del Templo $A$ de Azaila, Teruel (Beltrán, 1995, fig. 92), de fecha tardorrepublicana, que al parecer contenía un grupo ecuestre con ese mismo modelo iconográfico de un personaje heroizado (Nony, 1969, 26; Almagro-Gorbea, 1996, 130; AlmagroGorbea y Moneo, 2000, 78 s.).

Este contexto ideológico permite comprender por qué casi todas estas figuras están dispuestas sobre un doble capitel eólico, al menos los mejores ejemplares, que parecen ser los iniciales de la serie. Este elemento debe interpretarse como el "Árbol de la Vida", símbolo de la inmortalidad del jinete que aparece encima. Dicho elemento también aparece en la citada figura del "Guerrero sacrificando un carnero" (Almagro-Gorbea y Fernández-Miranda (eds.), 1983, 148, $\mathrm{n}^{\circ} 107$ ), por lo que cabe suponer que esta pieza quizás sea el extremo de una insignia similar a las de estos jinetes. La actitud sacrificial y la disposición sobre el agua de dicho guerrero indica su carácter mítico (Olmos, (ed.), 1992, 146 s.), por lo que quizás se trate de un antepasado heroizado del poseedor y ostentador de la pieza. En todo caso, los dobles capiteles protoeólicos de todas estas piezas y la desnudez de los jinetes confirman su condición heroica, con referencia a un plano mítico, no al real. Esta hipótesis es perfectamente aplicable a estos jinetes de "tipo La Bastida", que serían la representación del heros equitans hispanus, cuyas funciones social e ideológica quedarían de este modo precisadas y explicaría las profundas raíces que permiten comprender la popularidad alcanzada por esta ideología, que acabó dando lugar al "jinete ibérico" de las monedas (AlmagroGorbea, 1995). Además, la condición heroica de estas figuras debe considerarse asociada a un carácter solar del Más Allá, como se ha indicado para los ejemplares celtibéricos interpretados como signa equitum (Almagro-Gorbea y Torres, 1999,70 y 78 s.) y se ha propuesto para el conocido disco de terracota púnico de la necrópolis de Douimès, en Cartago, con un jinete con casco y escudo redondo que constituye el mejor paralelo de estas figuras fuera del mundo ibérico (Fantar, 1970, 19 s., lám. XV) y que parece responder, en fechas similares de fines del siglo VI o inicios del V a.C., a estas mismas concepciones escatológicas de heroización ecuestre, tan extendidas por todo el Mediterráneo en la Antigüedad (Benoit, 1954).

Pero conviene recordar que el estilo jonio-ibérico de estas piezas debió ser introducido desde el ámbito jonio-focense ampuritano. Este estímulo artístico permite pensar que las influencias socio-políticas e ideológicas que entraña este símbolo iconográfico proceden también de influencias jonio-focenses, pues el origen de las características estilísticas permite conocer el de los influjos ideológicos transmitidos a través de ellas (Almagro-Gorbea, 1983, 284-285; id., 1999, 92).

En efecto, el jinete es un tema bastante frecuente en el Arte Griego arcaico desde inicios del siglo Vl a.C., tras las reformas políticas y del ejército en las que la caballería pasó a ser sinónimo de aristocracia y riqueza (Helbig, 1902; Alföldi, 1965), como también ocurría en otras elites de la Antigüedad (Almagro-Gorbea y Torres, 1999, 83 s.). Este significado del caballo explica que las acuñaciones griegas de Emporion utilizaran el Pegaso como tipo emblemático (Guadán, 1968, 267 s.), pues era el caballo de un héroe mítico, Belerofonte. Esta elección reflejaría el poder de elites aristocráticas ecuestres que, como en Massalia, gobernarían la ciudad (Str. $6,3,4$ ), precisando lo poco que se sabe de su organización política (Domínguez Monedero, 1986; Almagro-Gorbea, $1996,245, n .15)$. La idea del caballo como sinónimo de aristocracia y riqueza debió pasar del mundo griego arcaico al ibérico como parece indicar el estilo jonio-ibérico de estas figuras y de las esculturas relacionadas (AImagro-Gorbea, 1983, 284 s.; id., 1996, 92; vid. supra, $\S 2$ ), un proceso que testimoniarían de forma muy especial estas piezas tan singulares, por lo que ofrecen un evidente interés histórico. 


\section{INTERPRETACIÓN HISTÓRICA}

En consecuencia, la aparición de estos pequeños signa equitum ibéricos procedería del mundo helénico, concretamente de las elites ecuestres ampuritanas, como un elemento ideológico inculcado desde la aristocracia ecuestre griega a la ibérica para resaltar su preeminencia social, hecho que contribuye a esclarecer el papel desempeñado por los focenses en la formación de la aristocracia ecuestre ibérica, contactos que dejan presumir relaciones mutuas entre ambos ámbitos aristocráticos.

Este marco explicativo permite interpretar históricamente la dispersión que ofrecen estas piezas (Fig. 11), en especial su aparición en la zona de Espejo, en el centro de Andalucía, y la probable procedencia de otro de estos bronces en los santuarios ibéricos de Sierra Morena. Esta dispersión debe relacionarse con la penetración de influjos greco jonio-focenses en los monumentos ibéricos de Andalucía Oriental y Central, que denotan, en la primera mitad del siglo $V$ a.C., un marcado ambiente filoheleno, semejante al de las regiones costeras del Sureste, reflejo de contactos con ese mundo colonial (Almagro-Gorbea, 1992, 46 s.; id., 1996, 83 y 92 s.). Junto al estilo grecoibérico de los monumentos se observan nuevas formas cerámicas e, incluso, algunos nombres ibéricos de ciudades andaluzas, elementos a los que hay que añadir ahora estos signa equitum, un objeto tan genuinamente ibérico y cuyo estilo denota los mismos contactos filohelenos.

La penetración de todos estos elementos hasta el centro de Andalucía reflejaría, en realidad, un proceso paralelo de "iberización", étnica y cultural, del substrato orientalizante precedente del mundo tartesio de la Andalucía Oriental y Central que debe enmarcarse en su contexto histórico. Al desaparecer Tartessos, a partir del tercer cuarto del siglo VI a.C., el mundo colonial focense, desde sus centros de Marsella y Ampurias, organizó una red de factorías hasta el Sureste, para, desde esta región, buscar por tierra el contacto con el antiguo Tartessos o como alternativa, dada la crisis de dicho territorio, las ricas regiones mineras del Sureste y de Sierra Morena.

En consecuencia, a fines del siglo VI o inicios del $\mathrm{V}$ a.C. un ambiente helenizante parece haberse extendido con relativa rapidez hacia el interior, alcanzando las tierras de la Meseta en la zona de Albacete (Blánquez, 1995; id., 1997) y penetrando en la Andalucía Orien-

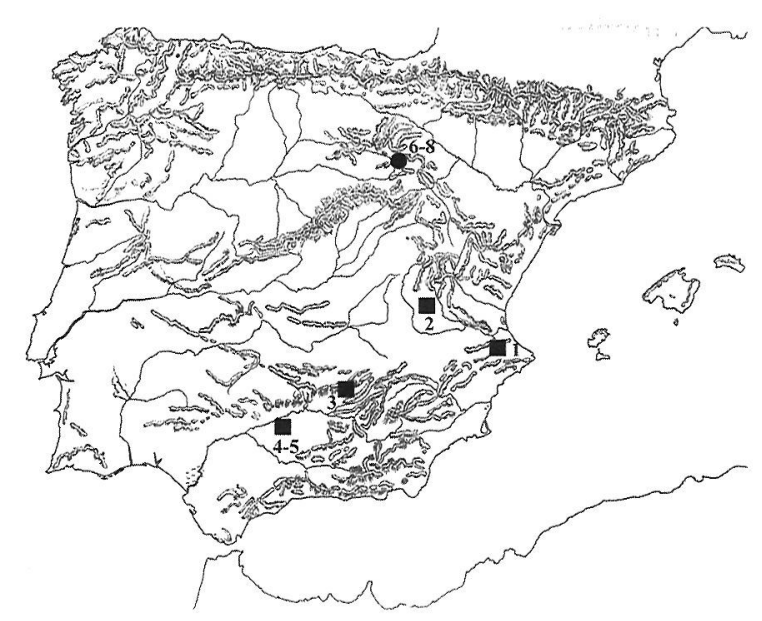

Figura 11: Mapa de dispersión de los signa equitum ibéricos (घ) y celtibéricos ( ): 1, La Bastida (Mogente, Valencia); 2 , Sureste de la provincia de Cuenca; 3 , provincia de Jaén; 4-5, zona de Espejo (Córdoba); 6, oppidum de Numancia (Soria); 7-8, necrópolis de Numancia (Soria).

tal hasta los santuarios de Sierra Morena (Almagro-Gorbea et al., 2004, 228 s.) y aún más allá, llegando a la ciudad oretana de Obulco, Porcuna (Negueruela, 1990), y hasta la zona de Espejo, la antigua Ucubi (Tovar, 1974, 114 s.), ya en el centro de Andalucía. Estos contactos con el Sureste Peninsular y la Alta Andalucía explican el creciente y marcado influjo grecooriental de la mejor escultura funeraria ibérica a partir de fines del siglo $\mathrm{VI}$ a.C. o inicios del siglo $V$ a.C., cuando se producen las mejores obras como los heroa de Ilici (Almagro-Gorbea, 1999) y de Obulco (Negueruela, 1990). En este sentido, ya se ha señalado cómo el Monumento de Pozo Moro, Chinchilla, Albacete, fechado hacia el 500 a.C., debe considerarse obra de artesanos del ámbito colonial fenicio, tal vez de Cádiz, como indican su estilo y sus complejas narraciones míticas orientalizantes (Almagro-Gorbea, 1983), pero, aunque el ajuar mantenía un ritual orientalizante de "jarro y brasero" para las libaciones, los objetos eran ya un oinochoe de bronce y un kylix y un lekythos áticos (AlmagroGorbea, 1983, lám. 14 y 15), cuya procedencia griega evidencia un cambio significativo en las corrientes comerciales, en los gustos y en la ideología de la clase dirigente contemporánea.

Este cambio ya se ha interpretado como indicio de una actitud filohelena del personaje regio allí enterrado (Almagro-Gorbea, 1992, 47; id., 1996, 92), pues se corresponde con la comentada intensificación de los influjos grecoorientales en la escultura ibérica documentados desde mediados del siglo VI a.C. en la costa del Sureste y acentuados en el primer cuarto del siglo $\mathrm{V}$ a.C., cuando penetran muy al interior, 
como testimonian las esculturas del herôon de Obulco, fechables antes del 480 a.C. (Negueruela, 1990, 302-303; Almagro-Gorbea, $1999,93)$ y el taller de los rizos largos del Santuario del Collado de los Jardines (AlmagroGorbea et al., 2004, 229 s.).

Estos hechos confirman la penetración creciente de influjos y relaciones filohelenas hacia el valle del Guadalquivir siguiendo la vía Herakleia en sentido contrario a como anteriormente se habían difundido los influjos económicos, culturales, políticos e ideológicos orientalizantes, cambio que coincide con el momento de máximo predominio griego en todo el Mediterráneo tras las Guerras Médicas y la batalla de Himera en Sicilia. Esta tendencia filohelena y los cambios estilísticos y sociales subyacentes parecen ir asociados a cambios ideológicos, probablemente originarios del mundo ibérico septentrional, de tradición indoeuropea (Almagro-Gorbea, 2001), que pudieron expandirse asociados a elites ecuestres guerreras de tipo heroico favorecidas, como se ha indicado, por su afinidad ideológica con sus semejantes del mundo griego focense, dado que participarían de parecidos conceptos heroicos originarios del mundo indoeuropeo que debieron mantenerse en las arcaizantes colonias focenses de Occidente. Dichas elites, aunque quizás también monárquicas como parece indicar el contexto arqueológico de signum equitum de La Bastida (Díes Cusí y Álvarez García, 1998, 336 s.; vid. supra, $\S 3$ ), respondian en todo caso a unas concepciones ideológicas totalmente diferentes de las monarquías sacras de tipo oriental de tradición tartésica, extrañas a la cultura griega y a su ideología y cuyos intereses estarian más vinculados a la colonización feno-púnica por tradición económica y afinidad ideológica. Esta hipótesis ayuda a explicar la estrecha asociación entre el cambio estilístico señalado, el correspondiente cambio ideológico, la expansión de la concepción «heroica» del poder político en las nuevas elites ecuestres ibéricas y también se pueden ver las citadas innovaciones en la extensión del rito de deponer armas en la sepultura y, por supuesto, en estos signa equitum como ostentación de la preeminencia social de las nuevas clases dirigentes.

Todo ello explicaría la competencia y las variaciones en las áreas de influencia de los dos grandes círculos coloniales de la Península lbérica: el feno-púnico en Andalucía y el greco-focense en el Levante y Sureste, desde donde presionaba hasta la segunda mitad del siglo $V$ a.C. sobre el anterior. La rivalidad existente favorecería y explicaría las habituales luchas entre las numerosas monarquias ibéricas de tipo guerrero gentilicio, dado el control indirecto o «protectorado» característico del sistema colonial, situación que permite explicar las frecuentes destrucciones de los monumentos ibéricos, a veces intencionales pero no contemporáneas, como consecuencia de su significado socio-político para la sociedad ibérica. En consecuencia, la penetración del estilo greco-ibérico por las zonas occidentales del antiguo mundo tartésico, como evidencian los elementos señalados, desde el herôon de Obulco a los signa equitum de Espejo, desde esta perspectiva, corresponderian a dinastias filohelenas.

Esta expansión de elites favorables a intereses comerciales griegos desde el Sureste hasta el centro del Valle del Guadalquivir puede explicar la iberización helenizante del área precedentemente tartésica del centro de Andalucía, que también se manifiesta en la producción cerámica y en la utilización de cráteras como urnas cinerarias (Pereira y Sánchez, 1985), pues los griegos favorecerían estas monarquías de tipo heroico frente a las monarquías sacras de tradición orientalizante. Además, alguno de estos influjos ibéricos filohelenos bien pudo ir asociado no sólo a profundos cambios políticos e ideológicos de las clases dirigentes, sino incluso a fenómenos étnicos, con los se podrían relacionar ciertos elementos lingüísticos ibéricos cuya dispersión coincide con la escultura monumental helenizante, como los topónimos ibéricos en ili-o ilu-, que se documentan por la parte oriental y meridional del mundo ibérico y que parecen haberse superpuesto en las áreas centrales de Andalucía a los topónimos en -ippo- y en -uba del substrato tartésico anterior (Untermann, 1985, 15, mapas 1, 2 y 5).

En consecuencia, estos bronces de tipo "Jinete de la Bastida", a pesar de su pequeño tamaño y de haber sido hasta ahora prácticamente desconocidos, ofrecen el interés de permitir comprender cómo se formó la elite gentilicia aristocrática ecuestre del mundo ibérico a partir, probablemente, de la arcaizante aristocracia ecuestre focense $y$, al mismo tiempo, precisar otras evidencias valoradas en estos últimos años sobre el desarrollo de las elites ecuestres del mundo ibérico, tan esenciales para entender el desarrollo de dicha cultura (Almagro-Gorbea, 1996, 77 s.) y confirmar la expansión, cada vez mejor documentada, de dichas elites hacia las zonas centrales de Andalucía. Por todo ello, estas pequeñas figuras de bronce son un documento histórico de indudable interés. 


\section{CONCLUSIONES}

Este conjunto de figurillas broncíneas de jinete "tipo La Bastida" configuran un grupo de gran homogeneidad tipológica, pues la mayoría repite un mismo modelo iconográfico, en el que el jinete desnudo porta un casco, de tipo jonio-ibérico, como el reproducido en las esculturas de Porcuna, con alta y elegante cimera, que, elevándose por encima, sobresale por delante del caballero, cayendo por la parte de atrás sobre sus hombros. El caballo porta, igualmente, un tocado sobre la frente, incidiendo en la actitud de parada que se desprende del conjunto. Todo ello aparece dispuesto sobre un soporte de cuyos extremos sobresalen sendos pares de volutas que cabe interpretar como la esquematización de otros tantos capiteles protoeólicos que nacerían de un vástago, trasunto del "Árbol de la Vida", que permitiría su enmangue en un astil de madera. Únicamente el jinete de La Bastida se aleja algo de tan homogéneo grupo, al ser la única figura completamente exenta y que porta una falcata y un escudo circular. Todas las piezas presentan, igualmente, similares dimensiones, lo que contribuye a dotar al conjunto de una mayor homogeneidad. Sus características estilísticas permiten proponer para este conjunto de piezas una cronologia a partir del segundo cuarto del siglo $\mathrm{V}$ a.C., pues alguna puede ser algo posterior a esta fecha.

La similitud estructural con piezas celtibéricas fechadas en el siglo II a.C. permite interpretarlas como signa equitum o estandartes propios del mundo ibérico, pudiéndose establecer su relación con elites aristocráticas ecuestres, cuya existencia queda confirmada por las representaciones escultóricas de caballeros formando parte de monumentos funerarios como los de Los Villares o el de Casas de Juan Núñez, o de heroa, como el conjunto de Porcuna, la antigua Obulco, todos ellos característicos de la fase heroica inicial de la cultura ibérica. En el plano ideológico, todas estas figuras parecen ser representación del heros equitans, seguramente interpretado como el antepasado mítico de las elites ecuestres, hecho que explicaría la aceptación y popularidad de este tipo iconográfico que acabó dando lugar al conocido "jinete ibérico" de las monedas hispánicas, en las que debe verse al héroe fundador de las poblaciones que las acuñaban.

Pero su mayor interés está en contribuir a explicar el origen y desarrollo de las elites ecuestres ibéricas por influjo de las focenses, además de documentar la expansión ibérica por las zonas centrales de Andalucía, lo que hace de estos objetos un elemento de indudable significado histórico.

\section{ADDENDUM}

Finalizado este trabajo, ha llegado a nosotros la noticia de la existencia de un vástago de bronce, que procedería al parecer del expolio de la sepultura en la que fue encontrado el "Jinete del Museo de Cuenca". A pesar de las dudas que genera este tipo de hallazgos, la posibilidad de que pudiera haber constituido el enmangue de dicha pieza, interpretada como un estandarte, aconseja su publicación, aunque al estar fracturado sólo se pueda apuntar el hecho. La pieza se encuentra depositada en el Museo de Cuenca (Inv. $n^{\circ} \mathrm{AA} /$ 05/43).

Se trata de un largo vástago hueco de sección prácticamente circular, fracturado en su extremo distal (Fig. 12). Esta realizado con una fina lámina de bronce batido doblada sobre sí misma y ligeramente solapada. En la base, una segunda lámina, igualmente de bronce batido, aunque en este caso estañada, envuelve a la anterior, observándose una perforación circular, quizás para fijar la pieza al astil de madera por medio de un clavo o pasador, aunque no pueda asegurarse tal funcionalidad, al no coincidir con la que supuestamente pudiera haber tenido la lámina inferior, pudiendo ser fruto de la corrosión. El conjunto queda reforzado por una pieza anular, realizada mediante fundición, con una moldura central maciza en forma de toro, que, a modo de presilla, contribuiría a fijar el conjunto mediante presión, observándose la impronta de la zona en la que dicha pieza realizaría su recorrido.

Como se ha señalado, el vástago aparece roto en su extremo, observándose la deformación del metal, con los rebordes doblados hacia dentro intencionadamente, lo que debió producirse después de la rotura. Igualmente, la pieza aparece deformada en lo que, en la actualidad, es la zona central del objeto, sin que llegara a producirse la fractura, siendo enderezada en el momento del hallazgo, como confirma el que haya saltado la capa de corrosión en la zona. Tales deformaciones serían fruto de sucesivas flexiones, realizadas posiblemente quizás para inutilizar el objeto antes de su amortización definitiva en la sepultura, como ocurre en ocasiones con los soliferrea y pila. 


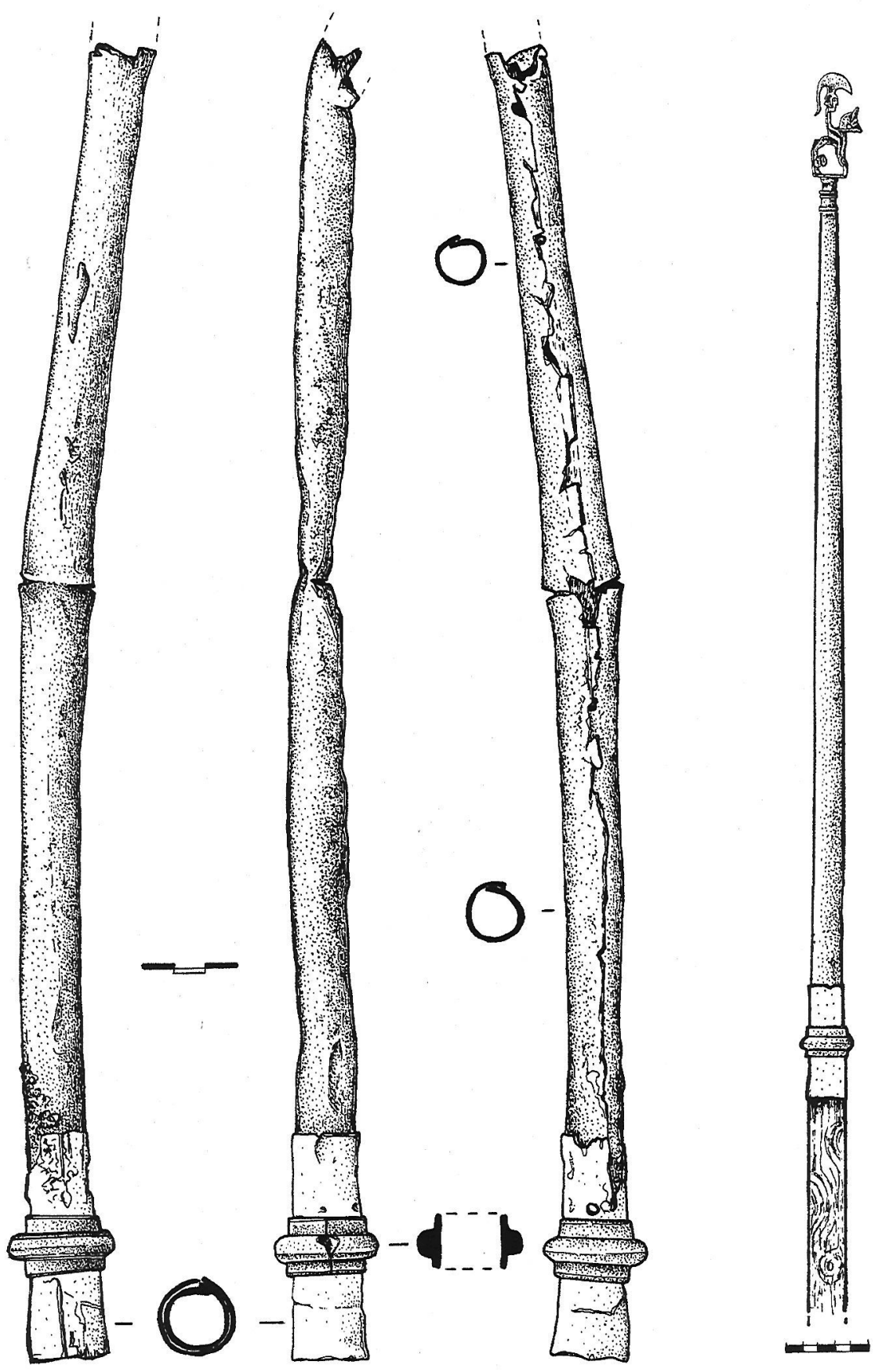

Figura 12: Vástago y propuesta de reconstrucción del cetro o estandarte del Museo de Cuenca.

La pieza mide $41 \mathrm{~cm}$, aunque posiblemente debió superar el medio metro, pues la forma en que se produjo la rotura permite pensar que ésta no se habría realizado en la proximidad de uno de los extremos del vástago. Presenta un diámetro más ancho en su base, donde alcanza los $2,5 \mathrm{~cm}$, facilitando así su enmangue mediante un astil de madera, para ir reduciéndose de forma progresiva -más evidente en la zona basal- hasta alcanzar los 1,8 $\mathrm{cm}$ en el extremo fracturado.
A pesar de la falta de documentación sobre las circunstancias del hallazgo, cabe suponer que esta pieza pudo haber estado rematada por la figura de jinete conservada en el Museo de Cuenca, puesto que algunos datos parecen apuntar en esa dirección. A las noticias relativas a su hallazgo conjunto, cabe añadir el sistema de enmangue que presenta la figura del jinete, mediante un vástago cilíndrico, decorado mediante molduras anulares con un doble toro, similares al que adorna la base de 
la pieza descrita. Dicho vástago, de $1,1 \mathrm{~cm}$ de diámetro máximo, presenta dos perforaciones que permitirían su fijación a un astil de madera, elemento éste que pudiera haber estado revestido por la lamina de bronce que hemos tenido la oportunidad de analizar, aunque la pérdida de su tramo distal impida confirmar la forma en que se produciría la unión. Con este sistema de enmangue, el conjunto no sólo quedaría reforzado estructuralmente, sino que ofrecería una mayor distinción, acrecentada por el brillo dorado propio del metal, acorde con la entidad del objeto, destacando en este sentido la utilización de una lámina estañada en la zona de la base, que proporcionaría un color más plateado que contrastaría con el dorado del resto de la pieza, constituyendo la evidencia más antigua del estañado del bronce en el mundo ibérico (S. Rovira, comunicación personal) ${ }^{7}$.

El "Jinete de Espejo 2" permitiría entender el aspecto que tendrían estos estandartes o cetros, cuyo remate y vástago sería de bronce, aunque la pieza cordobesa añada a su factura de menor calidad y a la ausencia de algunos de los elementos más significativos de este tipo de objeto, una simplificación del sistema de enmangue al sustituir las piezas tubulares huecas por una varilla maciza igualmente broncínea.

Más hipotético resulta calcular la longitud total que pudo tener este cetro regio o signum equitis ibérico. El dato más fiable es el diámetro de la moldura en forma de toro, ya que es la única pieza fundida y no deformada. Dicha pieza ofrece $3,45 / 3,50 \mathrm{~cm}$ de diámetro, lo que pudiera corresponder a $1 / 2$ palmo de $7 \mathrm{~cm}$ y a un pie ibérico de circa $28 \mathrm{~cm}$ (4 palmos $=1$ pié). Este pie de circa $28 \mathrm{~cm}$ podría relacionarse con el pie ibérico documentado en los monumentos escultóricos del Sureste (AlmagroGorbea y Ramos, 1986; Almagro-Gorbea, 1988, 125; Izquierdo, 2000, 398 s.), que, a su vez, se relaciona con un pie de 27,4 a $27,8 \mathrm{~cm}$ conocido como pie osco-campano (Peterse 1984; Hallier 1986) y, probablemente, con el llamado "pie de Glanum" de circa 28,2 cm (Roth Congès, 1985, 200; Almagro-Gorbea y Gran Aymerich, 1991, $188 \mathrm{~s}$.), todos ellos posiblemente derivados de una unidad de medida de origen colonial, en apariencia focense, extendida por amplias regiones del Mediterráneo Occidental, de la que también parece derivar el pie de circa $27,8 \mathrm{~cm}$ equivalente a $1 / 3$ de vara castellana de $83 / 84$ cm (Almagro-Gorbea, 2005).

Este pie ibérico de circa $28 \mathrm{~cm}$ permitiría, de forma hipotética, suponer que el cetro

midiera originariamente circa $56 \mathrm{~cm} \mathrm{(=2} \mathrm{pies}$ $=8$ palmos), incluyendo los de $8,5 \mathrm{~cm}$ de altura del jinete, lo que supondría un total de circa $47,5 \mathrm{~cm}$ para el mango del cetro dado a conocer en este addendum; otra posibilidad quizá no tan simple y lógica, es suponer para el cetro una longitud total de 2 pies, lo que supondría circa $56 \mathrm{~cm}$ de longitud total y añadir a esa longitud la altura de la figura del jinete, lo que daría para el cetro una altura total de $64,5 \mathrm{~cm}$.

Dimensiones: longitud conservada, $41 \mathrm{~cm}$; longitud de la lámina exterior, $6,8 \mathrm{~cm}$; diámetro del vástago, 1,5/1,8 cm (zona distal) $-2,3 \mathrm{~cm}$ (zona basal); diámetro de la chapa, $2,5 \mathrm{~cm}$ (base) - 2,15 cm; longitud de la presilla: 1,6$1,9 \mathrm{~cm}$; diámetro de la presilla, $2,45 / 2,6 \mathrm{~cm}$; diámetro del toro, $3,45 / 3,5 \mathrm{~cm}$; grosor, $0,1 \mathrm{~cm}$ (láminas) - 0,15/0,7 cm (presilla); peso, $200 \mathrm{gr}$. Análisis metalográfico ${ }^{8}$ :

Vástago (PA12025A): Cu: 93,07\%; Sn: 6,207; $\mathrm{Pb}: 0,28 \%$; Fe: 0,03 \%; Ni: nd; Zn: nd; As: nd; Ag: $0,131 \%$; Sb: 0,281\%.

Lámina exterior (PA12025C): Cu: 80,96\%; Sn: 14,899 ; Pb: 3,36 \%; Fe: 0,25 \%; Ni: nd; Zn: nd; As: nd; Ag: 0,061 \%; Sb: 0,479\%.

Presilla (PA12025B): Cu: 77,64 \%; Sn: 10,209; $\mathrm{Pb}: 11,0 \mid 6 \%$; Fe: $0,58 \%$; Ni: nd; Zn: nd; As: nd; Ag: 0,069\%; Sb: 0,439\%.

Prof. Alberto J. Lorrio Alvarado Area de Prehistoria Dpto. de Prehistoria, Arqueología, $H^{a}$ Antigua, Filología Griega y Filologia Latina

Facultad de Filosofía y Letras

Universidad de Alicante

Apdo. 99

03080 Alicante

alberto.lorrio@ua.es

\section{BIBLIOGRAFÍA}

AKURGAL., E., 1969: Orient et occident. La naissance de l'art grec, Paris.

AKURGAL, E., 2000: The Aegean Birth place of Western Civilization, Izmir

ALFÖLDI, A., 1965: "Die Herrschaft der Reiterei in Griechenland und Rom nach dem Sturz der Könige", Festchrift K. Scheford, 13-47, Bern.

ALMAGRO-GORBEA, M., 1976-78: "La iberización de las

\footnotetext{
7 Se conocen algunos bronces estañados en el mundo celtibérico, procedentes de las necrópolis de Almaluez y Clares (Rovira et al. 1996), pudiendo señalar la utilización de esta técnica en una fíbula de tipo La Téne I de la necrópolis de El Molón (Camporrobles, Valencia), en la cercana comarca de Utiel-Requena (Lorrio, 2001, fig. 7B).

${ }^{8}$ Agradecemos al Dr. Salvador Rovira la realización de los análisis metalográficos de la pieza.
} 
zonas orientales de la Meseta”, Ampurias, XXXVIII-XL, 93-156.

ALMAGRO-GORBEA, M., 1977: El Bronce Final y el Periodo Orientalizante en Extremadura, Biblioteca Praehistorica Hispana, XIV, Madrid.

ALMAGRO-GORBEA, M., 1983: "Pozo Moro. El monumento orientalizante, su contexto socio-cultural y sus paralelos en la arquitectura funeraria ibérica", Madrider Mitteilungen, 24, 177-392.

ALMAGRO-GORBEA, M., 1988: "El pilar-estela ibérico de Coy (Murcia)", Homenaje a Samuel de los Santos, 125 131, Albacete.

ALMAGRO-GORBEA, M., 1992: "Las necrópolis ibéricas en su contexto mediterráneo". Congreso de Arqueología Ibérica. Las necrópolis, 37-75, Madrid.

ALMAGRO-GORBEA, M., 1995: "La moneda hispánica con jinete y cabeza varonil ¿Tradición indígena o creación romana?", Zephyrus, 48, 235-266.

ALMAGRO-GORBEA, M., 1996: Ideología y Poder en Tartessos y el mundo ibérico. Discurso de ingreso en la Real Academia de la Historia, Madrid.

ALMAGRO-GORBEA, M., 1998: "Signa equitum de la Hispania céltica", Complutum, 9, 101-115.

ALMAGRO-GORBEA, M., 1999: El rey-lobo de La Alcudia de llici, Alicante.

ALMAGRO-GORBEA, M., 2001: "Los íberos: nuevas perspectivas sobre sus origenes", en A.J. Lorrio (ed.): Los iberos en la Comarca de Requena-Utiel (Valencia), 3347, Alicante.

ALMAGRO-GORBEA, M., 2005: "El conjunto de varas castellanas", Maier, J. (ed.), Catálogo de la Real Academia de la Historia. Siglos XVI a XX, Madrid (en prensa).

ALMAGRO-GORBEA, M., CASADO, D., FONTES, F., MEDEROS, A., y TORRES, M., 2004: Prehistoria. Antigüedades Españolas I. Catálogo del Gabinete de Antigüedades de la Real Academia de la Historia, I.2.1, Madrid.

ALMAGRO-GORBEA, M. y FERNÁNDEZ-MIRANDA, M. (eds.), 1983: Los iberos, Madrid.

ALMAGRO-GORBEA, M. y GRAN-AYMERICH, J., 1991: El Estanque Monumental de Bibracte (Mont Beubray, Borgoña), Complutum Extra 1, Madrid.

ALMAGRO-GORBEA, M. y MONEO, T., 2000: Santuarios urbanos en el mundo ibérico, Biblioteca Archaeologica Hispana, 4, Madrid.

ALMAGRO-GORBEA, M. y RAMOS, R., 1986: "El monumento ibérico de Montforte del Cid (Alicante)", Lucentum, $5,45-63$.

ALMAGRO-GORBEA, M. y TORRES, M., 1999: Las fibulas de jinete y de caballito. Aproximación a las elites ecuestres y su expansión en la Hispania céltica, Zaragoza.

ÁLVAREZ-OSSORIO, F., 1941: Catálogo de los exvotos de bronce ibéricos. Museo Arqueológico Nacional, Madrid.

ARANEGUI, C., MOHEN, J.P. y ROUILLARD, P. (eds.), 1998: Los Iberos. Príncipes de Occidente, Barcelona.

BALLESTER, I., 1931: Diario de Excavación de La Bastida (Les Alcuses), $n^{\circ} 38$, inédito.

BALLESTER, I., 1932: La labor del Servicio de Investigación Prehistórica y su Museo en el pasado año 1931, Valencia.

BELTRÁN, M., 1995: Azaila. Nuevas aportaciones deducidas de la documentación inédita de Juan Cabré Aguiló, Zaragoza.

BENOIT, F., 1954: L'Hérö̈sation équestre, Aix-en-Provence. BETANCOURT, P.P., 1977: The Aeolic Style in Architecture, Princeton, N.J.

BLANCO, A., 1987: "Las escuituras de Porcuna I. Estatuas de Guerreros", Biblioteca de la Real Academia de la Historia, CLXXXIV, 405-445.

BLÁNQUEZ, J., 1995: "La necrópolis tumular de Los Villares (Hoya Gonzalo, Albacete)", El mundo ibérico: una nueva imagen en los albores del año 2000, 238-245, Albacete.

BLÁNQUEZ, J., 1997: "Caballeros y aristócratas del s. V a.C. en el mundo ibérico", Iconografía ibérica-lconografia itálica: propuestas de interpretación y lectura, 211-234, Madrid.

BLÁZQUEZ, J.M.a, 1975: Tartessos y los origenes de la colonización fenicia en Occidente, Salamanca, $2^{a}$ ed.

BLECH, M., KOCH, M., y KUNST, M., 2001: Denkmäler der Frühzeit (Hispania Antiqua), Mainz.

BONET, H., 2001: "Los iberos en las comarcas centrales valencianas", en A.J. Lorrio (ed.), Los Iberos en la Comarca Requena-Utiel (Valencia), Anejo a la revista Lucentum, 4, 63-74, Alicante.

BONET, H., DIES, E., ÁLVAREZ, N. y PÉREZ JORDÁ, G., 1997: "La Bastida de les Alcuses (Moixent): resultados de los trabajos de excavación y restauración. Años 19901995", Archivo de Prehistoria Levantina, XXII, 215-295.

CAMÓN, J., 1954: Las artes y los pueblos de la España primitiva, Madrid.

CELESTINO, S. y ZULUETA, P. DE, 2003: "Los bronces de Cancho Roano", en S. Celestino (ed.), Cancho Roano IX. Los materiales arqueológicos, II, 9-123, Mérida.

CHAPA, T., 1980: La escultura zoomorfa ibérica en piedra, Tesis Doctoral de la Universidad Complutense, Madrid.

CHAPA, T., 1985: La escultura ibérica zoomorfa, Madrid.

DÍES CUSí, E. y ÁlVAREZ GARCİA, N., 1998: "Análisis de un edificio con posible función palacial: la casa 10 de la Bastida de les Alcuses (Moixent)", Saguntum Extra-1, 327-341.

DOMÍNGUEZ MONEDERO, A., 1986: "La ciudad griega de Emporion y su organización política", Archivo Español de Arqueologia, 59, 3-12.

FANTAR, M., 1970: Eschatologie phénicienne et punique, Tunis.

FERNÁNDEZ-MIRANDA, M. y OLMOS, R., 1986: Las ruedas de Toya y el origen del carro en la Peninsula lbérica, Madrid.

FLETCHER, D. y MATA, C., 1981: "Aportación al conocimiento de los ponderales ibéricos", Saguntum, 16, 165175.

FLETCHER, D., PLA, E. y ALCÁCER, J., 1965: La Bastida de les Alcuses (Mogente - Valencia), I, Servicio de Investigación Prehistórica, Serie de Trabajos Varios, 24, Valencia.

FLETCHER, D., PLA, E. y ALCÁCER, J., 1969: La Bastida de les Alcuses (Mogente - Valencia), II, Servicio de Investigación Prehistórica, Serie de Trabajos Varios, 25, Valencia.

FREY, O.H., 1991: “La formazione della cultura di La Tène nel V secolo a.C.”, I Celti, 127-146, Milano.

GUADÁN, A.M., 1968: Las monedas de plata de Emporion y Rhode, Anales y Boletín de los Museos de Arte de Barcelona, 12, Barcelona.

HALLIER, G., 1986: "Pierre de taille et mesures normalisées: les enceintes hellénistiques d'Apollonia de Cyrénaïque et de Massalia"; La fortification dans l'histoire du monde grec, 251-271, Paris.

HELBIG, W., 1902: "Les ippeîs Athéniens", Mémoires de I'Institut National de France, Academie des Inscriptions et Belles Letres 37, 157-264.

IZQUIERDO, I., 2000: Monumentos funerarios ibéricos: Ios pilares-estela, Trabajos Varios del S.I.P. 98, Valencia. 
JIMENO, A., 1994: "Investigación e Historia de Numancia", en J.L. Argente (coord.): El Museo Numantino, 75 años de la Historia de Soria, 25-61, Soria.

JIMENO, A., 1996: "Numancia: Relación necrópolis-poblado", Archivo Español de Arqueología, 69, 57-76.

JIMENO, A., REVILLA, M. ${ }^{a}$ L., DE LA TORRE, J.I., BERZOSA, R. y MARTÍNEZ, J.P., 2002: Numancia. Guia del yacimiento, Soria.

KUKAHN, E., 1954: "Estatuilla de bronce de un guerrero a caballo del poblado ibérico de "La Bastida de les Alcuses" (Mogente-Valencia)", Archivo de Prehistoria Levantina, V, 147-158. (= 1982: "Statueta de bronze d'un guerrer a cavall del poblat iberic de "La Bastida de les Alcuses" (Moixent València)", La bastida de les Alcuses. 50' Aniversari Declaració Monument Històric-Artistic Nacional (19311981), 7-13, Moixent).

LANTIER, R., 1935: Bronzes votifs ibériques, Paris.

LORRIO, A.J., 1997: Los Celtiberos, Complutum Extra, 7 , Alicante.

LORRIO, A.J., 2001: "El poblado y la necrópolis de El Molón", en A.J. Lorrio (ed.): Los Iberos en la Comarca RequenaUtiel (Valencia), Anejo a la revista Lucentum, 4, 151-170, Alicante.

LORRIO, A.J., 2004: "El armamento", en M.S. Hernándezy L. Abad (eds.): Iberia, Hispania, Spania. Una mirada desde llici, 155-166, Alicante.

LORRIO, A.J. y VELAZA, J., e.p.: "La primera inscripción celtibérica sobre plomo", Paleohispánica, 5.

LOSADA, H., 1966: La necrópolis de la Edad del Hierro de Buenache de Alarcón (Cuenca), Trabajos de Prehistoria, $X X$, Madrid.

MATA, C. y BONET, H., 1992: "La cerámica ibérica: Ensayo de tipología", Estudios de Arqueología ibérica y romana. Homenaje a Enrique Pla Ballester, Servicio de Investigación Prehistórica, Serie de Trabajos Varios, 89, 117-173, Valencia.

MÉLIDA, J.R., ÁLVAREZ, A., GÓMEZ SANTA CRUZ, S. y TARACENA, B., 1924: Ruinas de Numancia. Memoria descriptiva, Memoria de la Junta Superior de Excavaciones y Antigüedades, 61, Madrid.

MERGELINA, C. DE, 1926: El santuario hispano de la Sierra de Murcia, Memoria de la Junta Superior de Excavaciones y Antigüedades, 77, Madrid.

MONEO, T., 2004: Religio Iberica. Santuarios, ritos y divinidades (siglos VII-I a.C.), Bibliotheca Archaeologica Hispana, 20, Madrid.

NEGUERUELA, 1., 1990: Los monumentos escultóricos ibéricos del Cerrillo Blanco de Porcuna (Jaén), Madrid.

NICOLINI, G., 1968: "Geste et attitudes cultuels des figurines de bronze ibériques", Mélanges de la Casa de Velázquez, IV, 27-50.

NiCOLINI, G., 1969: Les bronzes figurés des sanctuaires ibériques, Paris.

NICOLINI, G., 1973: Les Ibères, art et civilisation, Paris.

NICOLINI, G., 1977: Bronces ibéricos, Barcelona.

NONY, C., 1969: "Une nouvelle interpretation des bronzes d'Azaila", Mélanges de la Casa de Velázquez, V, 5-30.

OLMOS, R. (ed.), 1992: La sociedad ibérica a través de la imagen, Madrid.

PASTOR EIXARCH, J.M., 1998: «Estandartes, insignias y heraldos ibéricos y celtibéricos», Emblemata. Revista Aragonesa de Emblemática, IV, 11-48.

PEREIRA, J. y SÁNCHEZ, C., 1985: «Imitaciones ibéricas de vasos áticos en Andalucia», Ceràmiques gregues $i$ hellenistiques a la Península lbérica, 87-102, Barcelona.

PETERSE, C., 1984: "Der oskische Fuss in pompejanischen
Atrien", Bulletin Antieke Beschaving, 59, 9-17.

PRADOS, L., 1992: Exvotos ibéricos de bronce del Museo Arqueológico de Nacional, Madrid.

QUESADA, F., 1997: El armamento ibérico. Estudio tipológico, geográfico, funcional, social y simbólico de las armas en la Cultura Ibérica (siglos VI-I a.C.), Monographies Instrumentum, 3, 2 vol., Montagnac.

RAMOS MOLINA, A., 2000: La escultura ibérica en el Bajo Vinalopó y el Bajo Segura, Elche.

RIPOLLĖS, P.P., 1999: "De nuevo sobre la localización de 1kale(n)sken", $1^{\text {a }}$ Jornadas de Arqueología Ibérica en Castilla-La Mancha, 145-168, Toledo.

ROTH-CONGÈS, A., 1985: "Glanum prérromaine: recherche sur la métrologie et ses applications dans l'urbanisme et l'Architecture" Revue Archéologique de la Narbonnaise, $18,189-220$.

ROVIRA, S.; GÓMEZ, P. y MONTERO, I., 1996: "Los bronces estañados de la Edad del Hierro: estudio tecnológico", Boletín del Museo Arqueológico Nacional, XIV, 31-37.

SCHULTEN, A., 1931: Numantia. Die Ergebnisse der Ausgrabungen 1905-1912. II. Die Stadt Numantia, München.

SHILOH, Y., 1979: The proto-aeolic capital and israelita ashlar masonry (Quedem 11), Jerusalem.

SIERRA, M., 1981: "Fuente de la Mota (Barchín del HoyoCuenca)", Noticiario Arqueológico Hipánico, 11, 209-306.

SIERRA, M., 2002: Yacimiento ibérico "Fuente de la Mota", Barchín del Hoyo, Cuenca, Cuenca.

SIERRA, M., 2003: "El yacimiento ibérico de Fuente de la Mota: los albores de una cultura en la Submeseta Sur de Cuenca", Investigaciones arqueológicas en Castilla-La Mancha, 1996-2002, 105-116, Toledo.

TARRADELL, M., 1968: Arte ibérico, Barcelona.

TOVAR, A., 1974: Iberische Landeskunde II. Die Völker und die Städte des antiken Spanien. 1, Baetica, Baden-Baden.

UNTERMANN, J., 1985: "Lenguas y unidades políticas del Suroeste hispánico en época prerromana”, en Chr. Wentzlatt-Eggebert (ed.): De Tartessos a Cervantes, 140, Köln-Wien.

VALERO, M.A., 1999: "La necrópolis tumular de la Punta del Barrionuevo, Iniesta-Cuenca», $1^{a}$ Jornadas de Arqueologia Ibérica en Castilla-La Mancha, 181-208, Toledo. 